\title{
Ethnopharmacological Study of Medicinal Plants in Bajwat Wildlife Sanctuary, District Sialkot, Punjab Province of Pakistan
}

\author{
Sidra Ahsan Shah, ${ }^{1,2}$ Wajeeha Iqbal, ${ }^{3,4}$ Muneeba Sheraz, ${ }^{5,6}$ Bilal Javed $\mathbb{D}^{7,8}$ \\ Syeda Sadaf Zehra, ${ }^{9}$ Hafiza Aniqa Bint E. Abbas, ${ }^{10}$ Waris Hussain, ${ }^{8}$ Abdullah Sarwer, ${ }^{11,12}$ \\ and Zia-ur-Rehman Mashwani ${ }^{8}$ \\ ${ }^{1}$ Allama Iqbal Medical College, Lahore, Punjab, Pakistan \\ ${ }^{2}$ Department of Internal Medicine, Basic Health Unit Noinwala Tehsil Wazirabad, Gujranwala, Punjab 52000, Pakistan \\ ${ }^{3}$ Khawaja Muhammad Safdar Medical College, Sialkot, Punjab 51310, Pakistan \\ ${ }^{4}$ Department of Internal Medicine, Basic Health Unit Ghagga Mitter, Wazirabad, Punjab 52000, Pakistan \\ ${ }^{5}$ Rawalpindi Medical University, Rawalpindi, Punjab 46000, Pakistan \\ ${ }^{6}$ Department of Internal Medicine, Basic Health Unit Mitranwali Daska, Sialkot, Punjab 52220, Pakistan \\ ${ }^{7}$ School of Food Science and Environmental Health, College of Sciences and Health, Technological University Dublin, \\ Dublin, Ireland \\ ${ }^{8}$ Department of Botany, PMAS Arid Agriculture University, Rawalpindi, Punjab 46300, Pakistan \\ ${ }^{9}$ Department of Botany, The Islamia University of Bahawalpur, Bahawalpur, Pakistan \\ ${ }^{10}$ Fatima Jinnah Medical University, Lahore, Punjab 54000, Pakistan \\ ${ }^{11}$ Nawaz Sharif Medical College, University of Gujrat, Gujrat, Punjab 50700, Pakistan \\ ${ }^{12}$ Allama Iqbal Memorial Teaching Hospital, Sialkot, Punjab 51310, Pakistan
}

Correspondence should be addressed to Bilal Javed; javedbilal87@gmail.com

Received 23 January 2021; Revised 20 September 2021; Accepted 28 September 2021; Published 25 October 2021

Academic Editor: Ian Cock

Copyright (c) 2021 Sidra Ahsan Shah et al. This is an open access article distributed under the Creative Commons Attribution License, which permits unrestricted use, distribution, and reproduction in any medium, provided the original work is properly cited.

\footnotetext{
Bajwat Wildlife Sanctuary is a complex riverine ecosystem and is unique because of the presence of river Chenab, various seasonal streams, lakes, and Head Marala barrage. These ecogeographic conditions provide diverse natural habitats for various plant and animal species to grow uninterrupted and have undocumented ethnopharmacologically important medicinal flora. The present study involves the first-ever extensive investigation to document the ethnopharmacological knowledge on medicinal plants of local healers and inhabitants of the Bajwat Wildlife Sanctuary to treat ailments. The unstructured and semistructured interviews of the local healers and inhabitants were conducted that included 130 individuals. The ethnomedicinal formulations, their method of preparation, mode of administration, parts of the plant used, diseases cured, and their categorization along with species use report (UR) were analyzed. The ethnopharmacological study led to the enlisting of 114 medicinal plant species belonging to 97 genera and distributed among 47 plant families. 2029 URs were collected with 42 general disease categories. Each plant species was reported 18 times to cure various diseases ( 18 UR), while $\sim 48$ URs were collected on each disease category by local informants. Digestive issues (290 URs, $14.29 \%$ ) and skin infections (279 URs, $13.75 \%$ ) were found most commonly among the occupants of the area. The oral administration (69\%) of herbal drugs and the preparation of plant extracts $(32 \%)$ were the most common ethnopharmacological strategies. Inhabitants of the area were well aware of the limited use of poisonous plants. $8(\sim 7 \%)$ out of the total 114 medicinal plant species were listed in the IUCN Red List of Threatened Species as Least Concern, while Eucalyptus camaldulensis Dehnh. was enlisted as near-threatened. The results of the present investigation show that the occupants of the Bajwat have sound information about the ethnopharmacological consumption of medicinal plants, and some of the novel ethnomedicinal formulations were reported which provide the basic data for further pharmacological research.
} 


\section{Introduction}

The traditional herbal medicine system in Pakistan is originated from Ayurveda medicine which has a history of 2500-600 BC [1]. The first documented record of the use of plant medicine in the subcontinent (Indo-Pak) is available in Rigveda (Rigveda is the oldest religious book of the Hindu religion. Many herbal remedies are documented in this book to treat ailments.) and dates to 4500-1600 BC. The herbal medicine system in Pakistan is greatly influenced by the traditional Chinese medicine system, Persian medicines, Greek medicine system [2], and prescriptions from the Prophet Muhammad (PBUH). The Tib-Al-Nabwi or Prophetic Medicine system has 1500-year-old history [3, 4]. These diverse features of the traditional healthcare system of Pakistan embellish it with great potential to use plants to treat various ailments.

The tertiary healthcare system in Pakistan is responsible to provide basic to advanced healthcare facilities to the inhabitants. The rural areas in Pakistan have limited healthcare services. Rural healthcare communities have facilities in the form of Rural Health Centers (RHCs) and Basic Health Units (BHUs) that contribute to cover a population of 25,000 inhabitants and are responsible to provide primary healthcare and referral services $[5,6]$. Most of the rural communities of Pakistan use herbal medicines because of the limited access to primary healthcare services, expensive medicines, and diagnostic tests [7]. Pakistan is blessed with a great number of higher plants $(5,700)$. Out of the enlisted higher plants, 600-700 are enumerated as therapeutic plants utilized by around registered herbalists and homeopaths. The pharmacopeia endorsed by the National Council of Tibb (Herbalist committee) enlisted 900 medicinal plants commonly used in Pakistan to prepare herbal medicines $[8,9]$.

Bajwat is situated in the district Sialkot $\left(32^{\circ} 62 \mathrm{~N}\right.$ and $\left.74^{\circ} 60 \mathrm{E}\right)$ and on the outskirts of the district Narowal region of Punjab territory in Pakistan (Figure 1). It contains 84 towns or small villages, with a population of 60,000 as indicated by the 2017 survey. The territory is a wetland of universal significance because of the nearness of Marala Headworks (barrage), Munawar Tawi (river), Jammu Tawi (river), and numerous natural streams, lakes, and muddy regions. Bajwat is situated in a transitional zone between the slopes of Jammu in Indian-occupied Kashmir and the plain zone of Punjab. Bajwat Wildlife Sanctuary has an absolute region of 5,464 hectares which provides free space to wildlife flora and fauna [10]. The most common and universally rare vertebrates of the area include the wild pig or wild boar (Sus scrofa L.), deer (Odocoileus virginianus Zimmermann), and nilgai (Boselaphus tragocamelus Pallas) (blue bull, largest Asian antelope) [11]. These special ecogeographic attributes and the presence of important plant and animal species and serious threats to them contributed to getting the special status for the area [12]. The vast floristic wealth and the rich knowledge of the inhabitants of Bajwat require necessary steps to document this traditional ethnopharmacological knowledge which can help forest officials, NGOs, policymakers, local healers, and researchers that are involved in ethnopharmacological research on medicinal plants. There are very few ethnobotanical studies on medicinal plants reported previously from the district Sialkot [13-17]. These studies were performed superficially, do not provide detailed ethnomedicinal knowledge of the district Sialkot, and do not cover Bajwat Wildlife Sanctuary. The importance of the ethnopharmacological consumption of the medicinal plants of Bajwat Wildlife Sanctuary was ignored, and there was no study to document the significance of the conserved flora.

It was hypothesized that the long-term and well-driven ethnopharmacological survey on medicinal plants of Bajwat Wildlife Sanctuary may help us to enlist ethnopharmacologically important medicinal plants of the area. It can be the first-ever study to document the ethnopharmacological knowledge of the local inhabitants and healers to use plants to treat diseases.

1.1. Aim of the Study. The present study was aimed to significantly establish the first-ever inventory of therapeutically important medicinal plants of the Bajwat Wildlife Sanctuary, which is endowed with unique biodiversity and gained a special status to conserve the local flora and fauna. The main objective of this study involves the enlisting of therapeutically significant plant species, their medicinal properties, and methods of preparation of the herbal formulations used by the inhabitants of Bajwat to treat ailments. A bibliographical comparison of the floral diversity of the studied area with the previously published scientific literature from the district Sialkot and with the Herbal Pharmacopeia of Pakistan was performed to determine if the species were reported earlier with similar ethnomedicinal preparations at a regional or national level or if it is reported for the first time in this context.

\section{Materials and Methods}

2.1. Study Area and Climate. Bajwat is a small village that is located in the district Sialkot, province of Punjab, Pakistan. Sialkot highlights a humid subtropical atmosphere according to the Köppen-Geiger atmosphere classification, with four seasons [18]. The postmonsoon (rainfall season) season from mid-September to mid-November stays hot during the daytime, yet the evenings are cooler with low humidity. In the winter from mid-November to March, days are moderate to cold, with once-in-a-while substantial rainfall. The temperature in winter may drop to $0^{\circ} \mathrm{C}$, yet maximum is rarely under $15^{\circ} \mathrm{C}$ [11]. The precipitation in the region is very high, which sometimes results in flooding and washing of economically important crops. The normal precipitation is $965 \mathrm{~mm} \mathrm{[12].}$

The main source of income for the general population is the cultivation of crop plants such as wheat and rice. They also raise livestock for dairy and profit. The people of the Bajwat have their ethnic linkage with the Kashmir province, and the majority of inhabitants are Muslims by religion. Bajwat Wildlife Area was declared as a sanctuary in 1964 by the Government of Pakistan to protect deer, wild pig, and nilgai from hunting and to prevent other serious threats to the flora. The Bajwat Wildlife Sanctuary is enlisted by the 


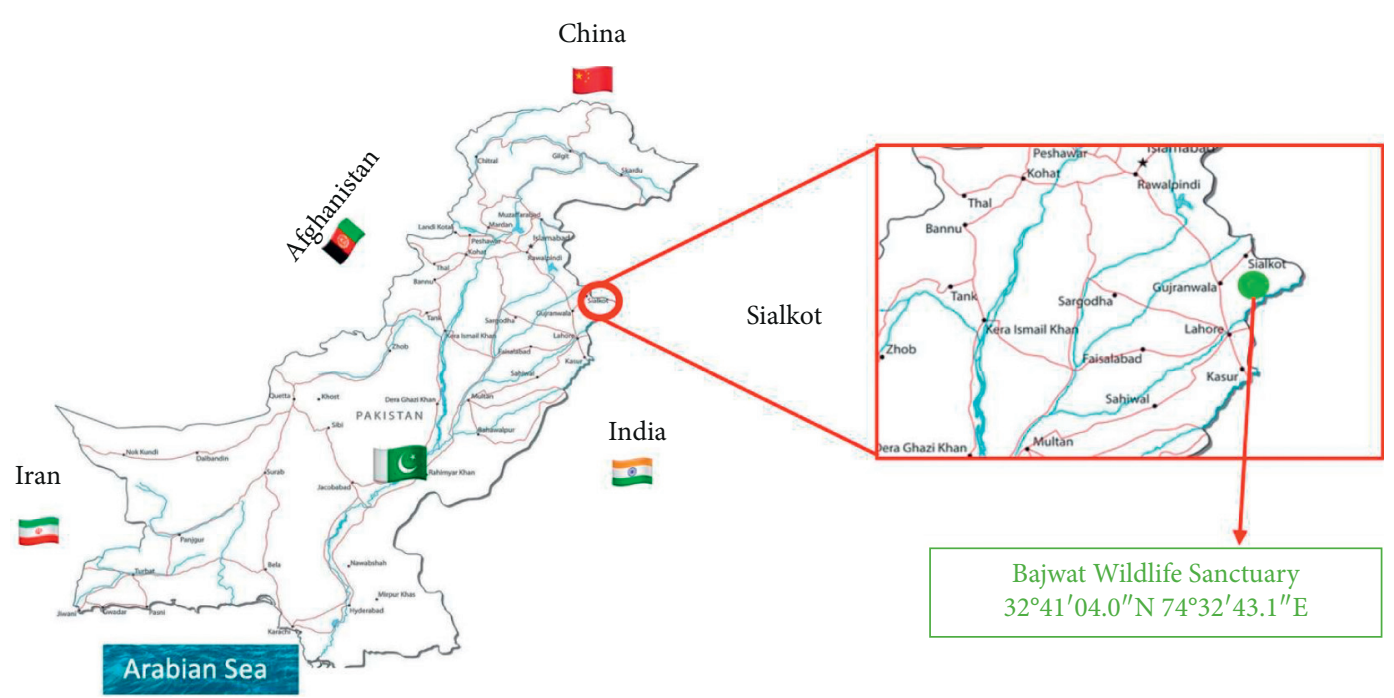

FIgure 1: The map of Pakistan showing its neighboring countries and the site of the study. The south of Pakistan is lined by the Arabian coast. The red highlighted map shows the location of Sialkot and the green dot represents the location of the Bajwat Wildlife Sanctuary.

IUCN as a classification IV area, which incorporates a complex of common riverine living spaces, close to the Sialkot along the Chenab River and two of its tributaries, reaching out up to the Indian outskirts (Figure 2). The area is usually inaccessible for a large population and is abandoned due to escalated tensions in the adjacent countries as the east side of the area moves along the Indian border [10]. The main realized danger is the unlawful chasing or hunting of animals, for which the zone has been announced as a Game Reserve and is protected by the Wildlife Department of the Government of Punjab, Pakistan. Below Bajwat is a place where the Chenab (river), Jammu (Occupied Kashmir, India), Tavvi (river), and Manavar Tavvi (river) meet at one spot. The Marala Headworks is situated in Bajwat's southwest corner, is a reservoir of the Chenab river water, and contributes to divert water in different territories of adjacent areas to irrigate field crops. The territory between these two channels is being created as the Marala Barrage Park [11]. These special ecogeographic attributes along with our interest led us to choose this region for our study.

2.2. Selection of Informants. The informants who had ethnopharmacological knowledge of medicinal plants and used crude formulations in the past or using in routine to treat ailments were selected [19].

\subsection{Ethnopharmacological Survey on Medicinal Plants and} Data Collection. Open meetings were arranged, in which the individuals were met through casual discussion. Every member was interviewed separately, and the data were recorded with great care. The point of open meetings was to evoke people to talk openly, without any stress or anxiety and to collect information about the medicinal attributes of plants that they utilize or have utilized previously. The second step was semiorganized meetings to acquire detailed quantitative and qualitative data and to obtain a wide range of knowledge on explicit issues. The routine activities of the people of Bajwat
Wildlife Sanctuary were observed during the study. A composed questionnaire was designed to collect data containing the name, sex, age, and address. In addition, the level of education of the interviewees and the spot and date of the meeting was recorded. The conversation with the interviewees was in Urdu and Punjabi languages. The questionnaires were filled by the researchers. The ethnopharmacological information consisting of the ethnomedicinal properties of the plant, the vernacular name, the plant parts utilized to prepare medicines, plant occurrence, credited therapeutic properties, and the techniques for preparing ethnopharmacological formulations was recorded $[20,21]$.

2.4. Collection of Plant Samples and Their Identification. The plant samples were collected from the Bajwat Wildlife Sanctuary with the help of local healers, herbalists, sellers, and informants. The study area was surveyed from January to the end of November 2019. The plants were identified by the author Waris Hussain with the help of the Flora of Pakistan. The herbarium sheets containing plant specimens were deposited in the herbarium of the Botany Department of PMAS-Arid Agriculture University, and accession numbers were allotted for future reference [22]. The correct and approved botanical names were enlisted throughout this study after verification from the Pakistan Plant Database (eFlora of Pakistan) (https://www.tropicos.org/Project/ Pakistan) and Plant List (http://www.theplantlist.org/).

2.5. Quantitative Data Analysis. The data collected from Bajwat was loaded on the Microsoft Office ${ }^{\circledR}$ program MS Excel $^{\circledast}$ spreadsheet. The graphs were plotted, and the data were evaluated in the form of percentages and proportions. The species use reports (URs) per herbal formulation were also recorded, and the greater number of informants per herbal formulation was considered as an indicator of excessive use of that plant in crude drug preparations. The use reports are defined as the number of informants per herbal 


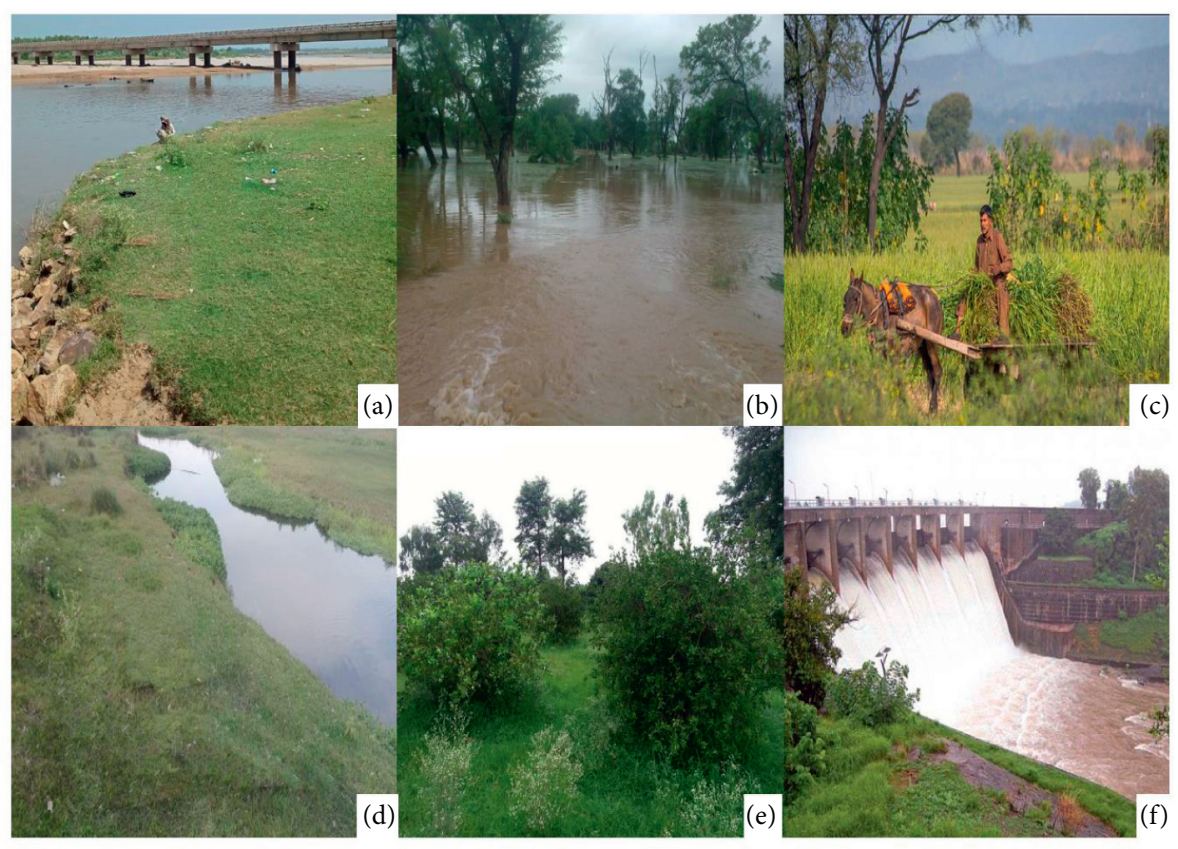

Figure 2: The photographic images of different areas of the Bajwat Wildlife Sanctuary. (a) Bridge on the river Tawi and the grassland; (b) the forest is flooded with water during monsoon season after heavy rainfall; (c) the inhabitant is using an animal cart to carry plants; (d) waterways in the study area; (e) plants growing freely in the protected area; (f) Head-Marala barrage.

formulation or ethnopharmacological preparation $[21,23,24]$. Information was considered coherent when it was reported by two individuals at different times. The diseases reported from the Bajwat Wildlife Sanctuary were arranged according to the international disease categories (ICPC-2, International Classification of Primary Care) by WHO (https://www.who.int/classifications/icd/adaptations/ icpc2/en/). Reported 114 medicinal plant species were searched in the IUCN Red List of Threatened Species (https://www.iucnredlist.org/) to determine their conservation status.

\section{Results and Discussion}

Bajwat Wildlife Sanctuary is a protected area that allows a great number of plant and animal species to proliferate freely without any human intervention. The studied area is a complex of different riverine and terrestrial territories that provide a great diversity of ecosystems and environmental conditions for the growth and reproduction of various varieties of plant species. To achieve the study goals and to test the hypothesis, 130 individuals, including 80 male and 50 female participants were interviewed. The local respondents belonged to different age groups ranging from 20-71/above. They had different levels of education from primary to university, while $15 \%$ of the informants were enlisted as illiterate (Table 1). The seventh author was originally from one of the villages of Bajwat (Pul-Bajwan). He and his family helped greatly to meet local inhabitants and some known healers of the area. The plant vernacular names are also enlisted in Table 2. The vernacular names were similar in both Urdu and Punjabi languages, and it was not possible to differentiate them based on the language. Ten male herbalists (registered with the National Council of Tibb, Pakistan) were also reported from the studied area. It was observed that the male informants were having more detailed knowledge about the plants' local names, their identification, and collection, while the female participants were having significant information regarding the method of preparation of herbal formulations, and their mode of administration.

3.1. Medicinal Plants Diversity in Bajwat Wildlife Sanctuary. The ethnopharmacological survey on medicinal plants of the Bajwat Wildlife Sanctuary led to the collection of 47 plant families and 114 medicinal plant species disseminated among 97 genera (Table 2). The distribution of the plant families to be used in ethnopharmacological medicines among the inhabitants of Bajwat Wildlife Sanctuary can be consulted in Figure 3. 10\% of the total reported medicinal plant species belong to the family Leguminosae/Fabaceae. Poaceae and Solanaceae occupied the $2^{\text {nd }}$ rank $(7 \%)$ in the context of the widely exploited medicinal plant species in the Bajwat Wildlife Sanctuary followed by Moraceae (6\%), Asteraceae (5\%), Apiaceae, Brassicaceae, Cucurbitaceae, Lamiaceae, and Rosaceae ( $4 \%$ each). Caesalpiniaceae was found to be 3\% among the reported species. Fabaceae, Poaceae, Solanaceae, and Moraceae account for 30\% of the total reported medicinal plant species of the area. The rest of the families were counted as $2 \% /<2 \%$ separately. A similar trend of utilization of medicinal plant families was reported (Farrukh Nisar et al., 2011; Zereen et al., 2013; Rashid et al., 2014) from the flora of Sialkot unlikely the Pakistan Plant Database (Flora of Pakistan) shows Asteraceae as the largest 
TABLE 1: Statistic and Socio-cultural factors of Interviewees.

\begin{tabular}{|c|c|c|c|}
\hline Factors & Items & Numbers $(\widehat{0}+q)$ & Percentage \\
\hline \multirow{2}{*}{ Gender } & Male & 80 & 61.53 \\
\hline & Female & 50 & 38.46 \\
\hline \multirow{6}{*}{ Age groups } & $20-30$ & $23+7$ & 23.07 \\
\hline & $31-40$ & $27+8$ & 26.92 \\
\hline & $41-50$ & $12+13$ & 19.23 \\
\hline & $51-60$ & $10+10$ & 15.38 \\
\hline & $61-70$ & $6+9$ & 11.53 \\
\hline & 71 and above & $2+3$ & 3.84 \\
\hline Herbalist & Male & 10 & 7.69 \\
\hline \multirow{7}{*}{ Educational level } & Illiterate & $12+8$ & 15.38 \\
\hline & Primary & $20+15$ & 26.92 \\
\hline & Middle & $5+5$ & 7.69 \\
\hline & High school & $12+8$ & 15.38 \\
\hline & Higher secondary & $20+10$ & 23.07 \\
\hline & University & $7+3$ & 7.69 \\
\hline & Others & $4+1$ & 3.84 \\
\hline
\end{tabular}

$\delta^{t}$ represents male participants, and $q$ represents female participants.

medicinal plant family countrywide (https://www.tropicos. org/Project/Pakistan).

The lifeforms provide great diversity and physiognomic contrast to the ecological habitat. The most common life forms (Figure 4) are reported in the ascending order for the preparation of herbal medicines such as herbs, shrubs, and trees. Some previous ethnobotanical studies on medicinal plants of the district Sialkot also reported herbs as the extensively utilized plant species to treat ailments of the local inhabitants $[13,14,16,17]$.

\subsection{The Traditional Source of Knowledge and Bibliographic} Comparison. The inhabitants of the Bajwat have sound traditional ethnopharmacological knowledge of medicinal plants because of the ancestral strong linkages among nearby individuals and families. The individuals acquire traditional knowledge from the seniors of the clans and keep on transferring it from one generation to another generation. Along these lines, nearby individuals gather therapeutic plants and treat themselves at home. Most of the senior people of the family, who practice medicine, help and guide their other family members and neighboring communities in the treatment of ailments. Both the male and female members of the society were playing a promising role in the transmission of ethnopharmacological knowledge to their next generation. The females used to guide their daughters and their daughters-in-law about the method of preparation of ethnopharmacological preparation and their mode of administration, while the male family members were going with their young kids to collect plants.

The traditional healers revealed from the studied area were having sound information on ethnopharmacologically significant medicinal plants, their method of preparation of formulations, and their mode of administration. The bibliographic comparison with the existing data from the district Sialkot led to the enlisting of 85 new medicinal plant species with novel herbal formulations not reported previously in the published scientific literature which makes $\sim 75 \%$ of the total collected medicinal plant species (Table 2). The ethnopharmacological comparison of the herbal formulations reported from the Bajwat Wildlife Sanctuary with the Pakistan Herbal Pharmacopeia [8] reported 24 new herbal remedies that make $21 \%$ of the total enlisted herbal formulations. The species with similar herbal formulations in different ethnomedicinal studies from the district Sialkot are enlisted in the last column of Table 2.

3.3. Plant Parts Used in Herbal Therapy. The different plant parts have different properties which help them to treat therapeutic ailments and likewise have significance in crude herbal formulations. $59 \%$ of the plants reported from the studied area were edible medicinal plants which show that these plants can be consumed in different forms to treat ailments, e.g., oral intake of drugs and food supplements to treat malnutrition, etc. while $41 \%$ of the medicinal plant species were not edible (Figure 5(a)). It shows that most of the plants of the studied area have their utility as food along with their medicinal applications. Figure 5(b) shows that $51 \%$ of reported plant species have their only use in herbal medications while $21 \%$ of plants were used as a source of timber followed by $14 \%$ of ornamentals in addition to their other medicinal properties. $8 \%$ of the plants were utilized as animals' medicine. Most of the animal medicines were given as fodder to treat animals' digestive issues. Some plants were given to animals as a food supplement while some plants were reported effective to eradicate malnutrition. A herbal formulation was prepared from Argemone mexicana L. root extract and applied topically to treat animals' skin issues. $6 \%$ of the plants of the studied area were exploited as a source of dietary fiber to treat digestive ailments.

The leaves, roots, wood or bark, flowers, herbaceous stem, fruit, and latex were found useful in a multitude of ethnopharmacological drugs, while some herbal formulations involved the use of whole plant material. Figure 5(c) shows that leaves and fruits play a significant role to make herbal remedies and stand out 19\% separately from both 


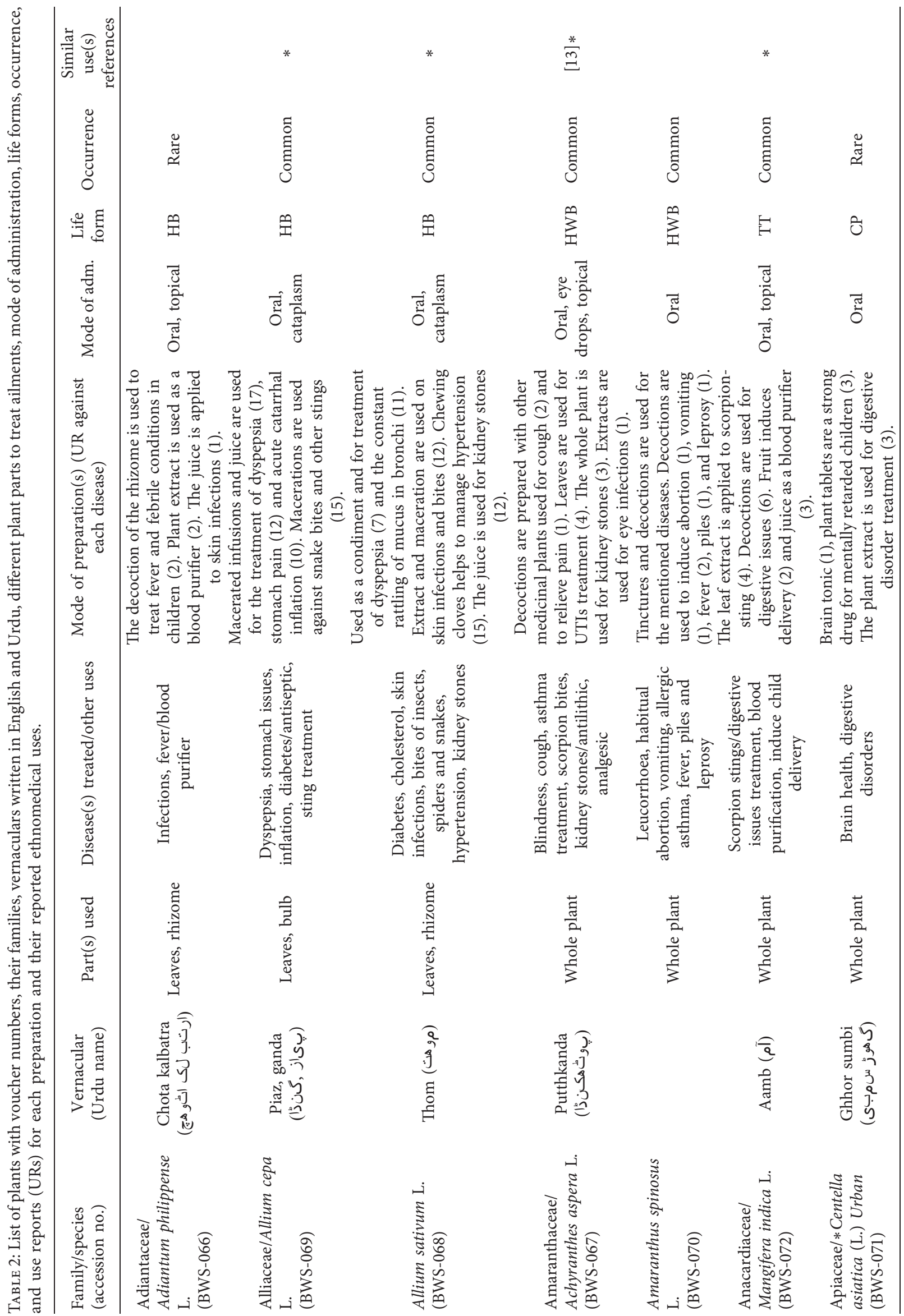




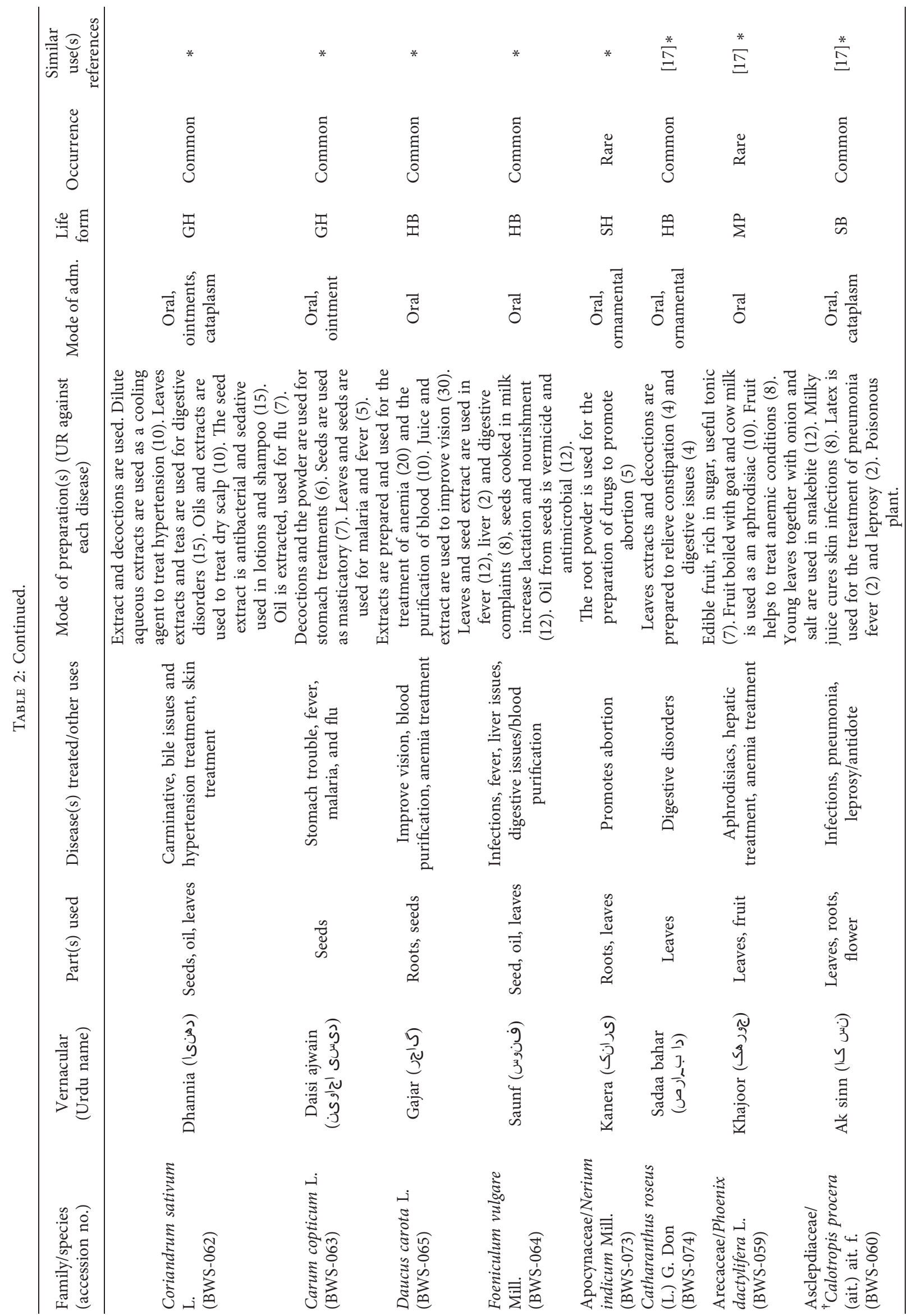




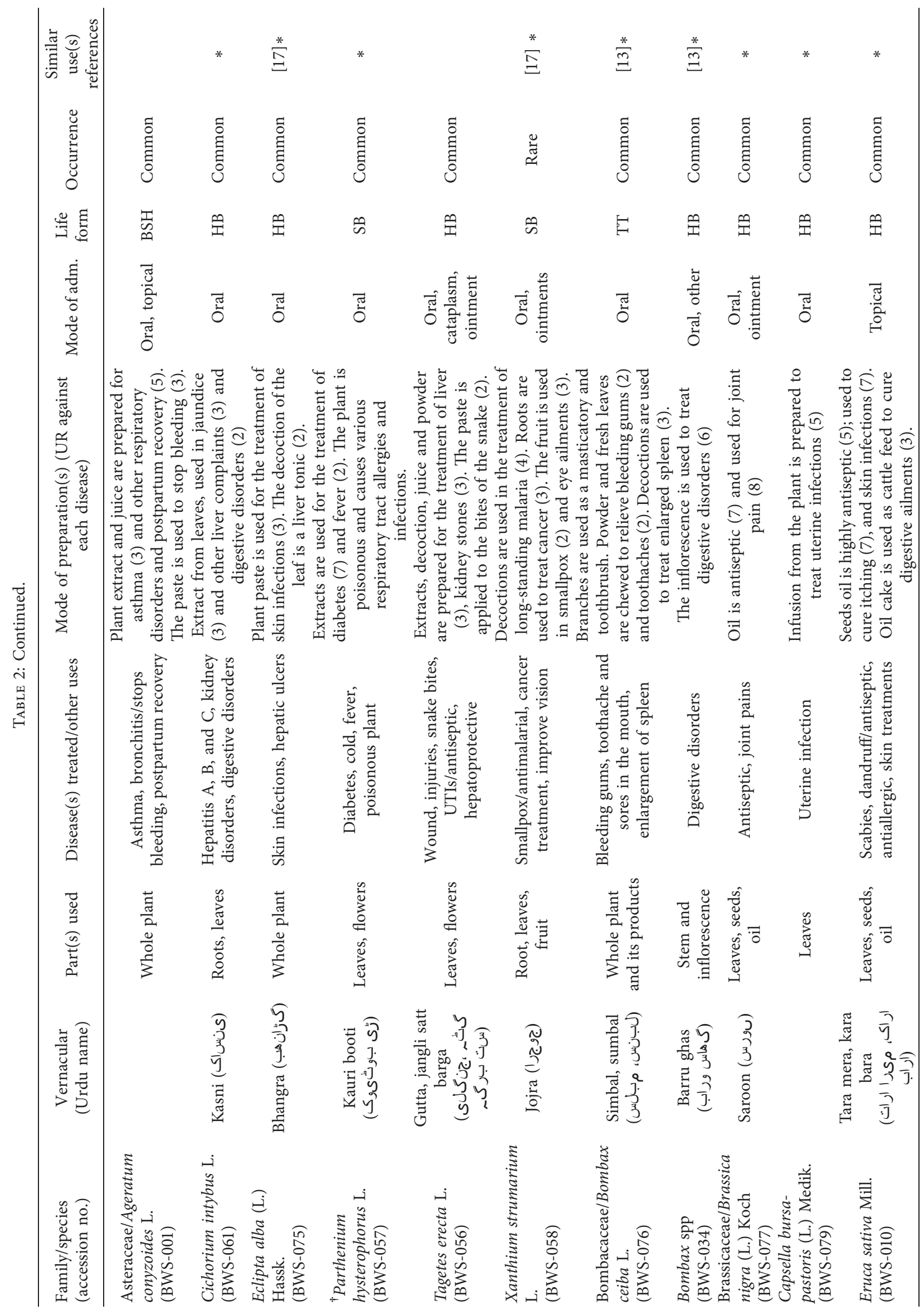




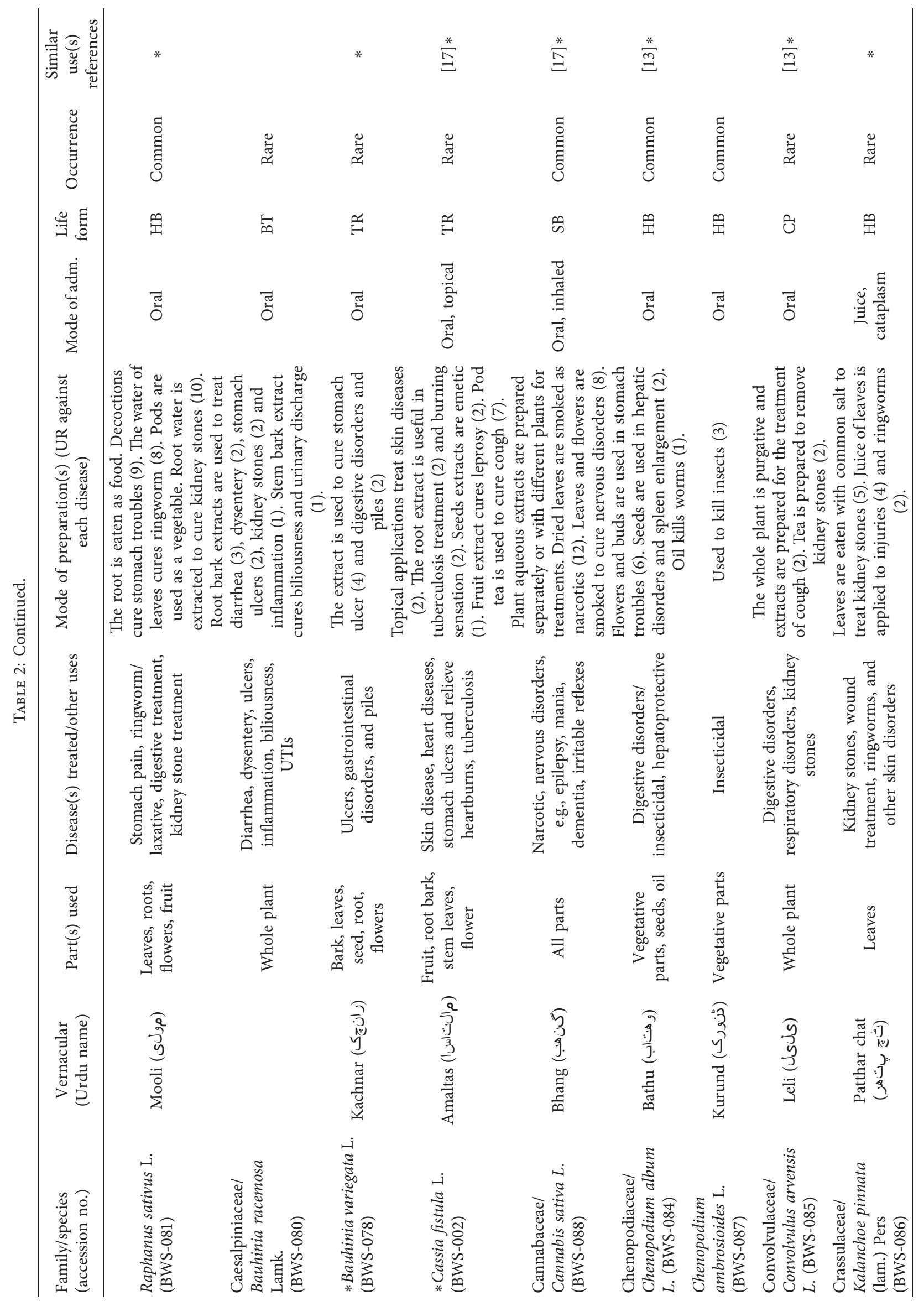




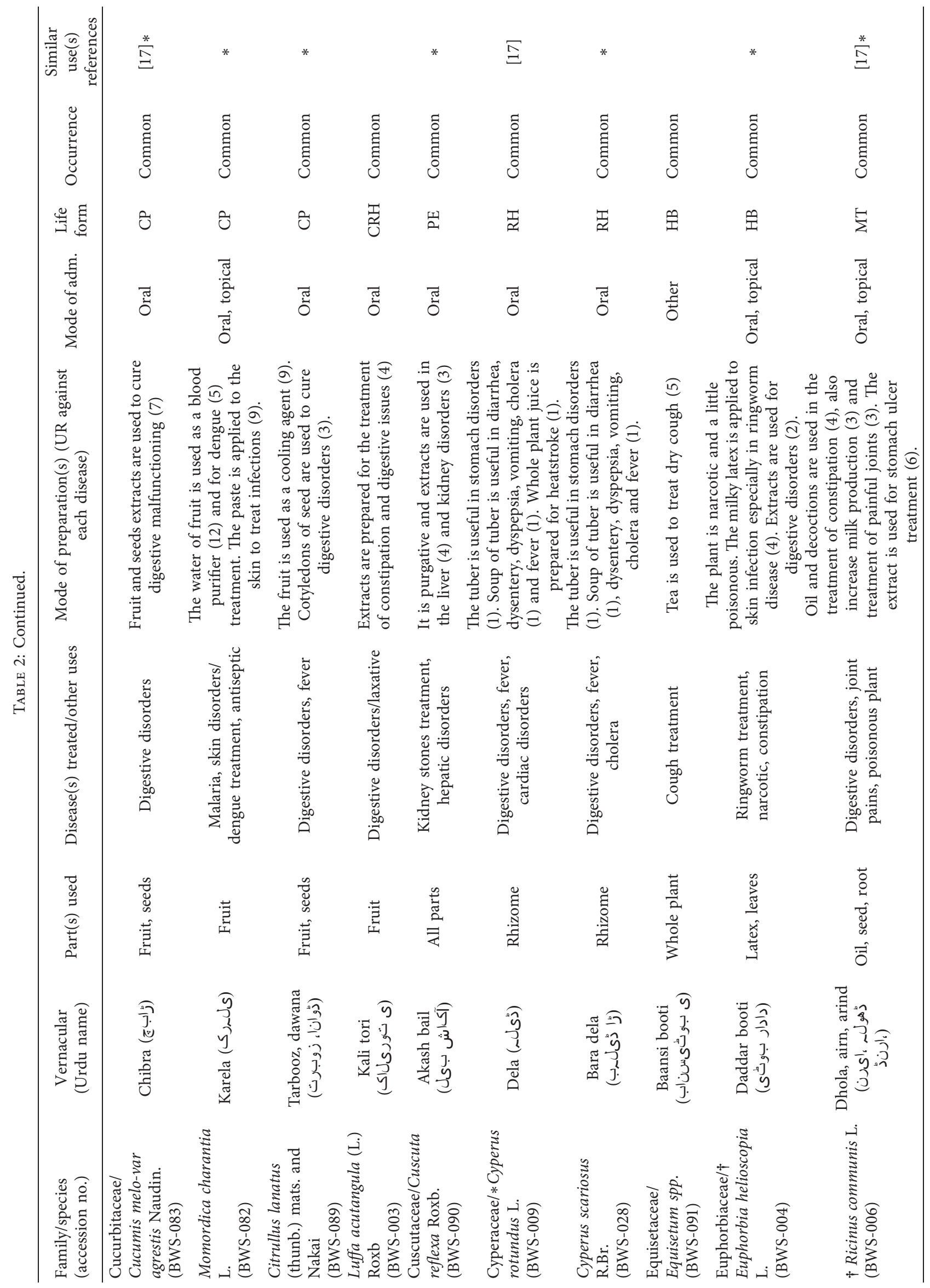




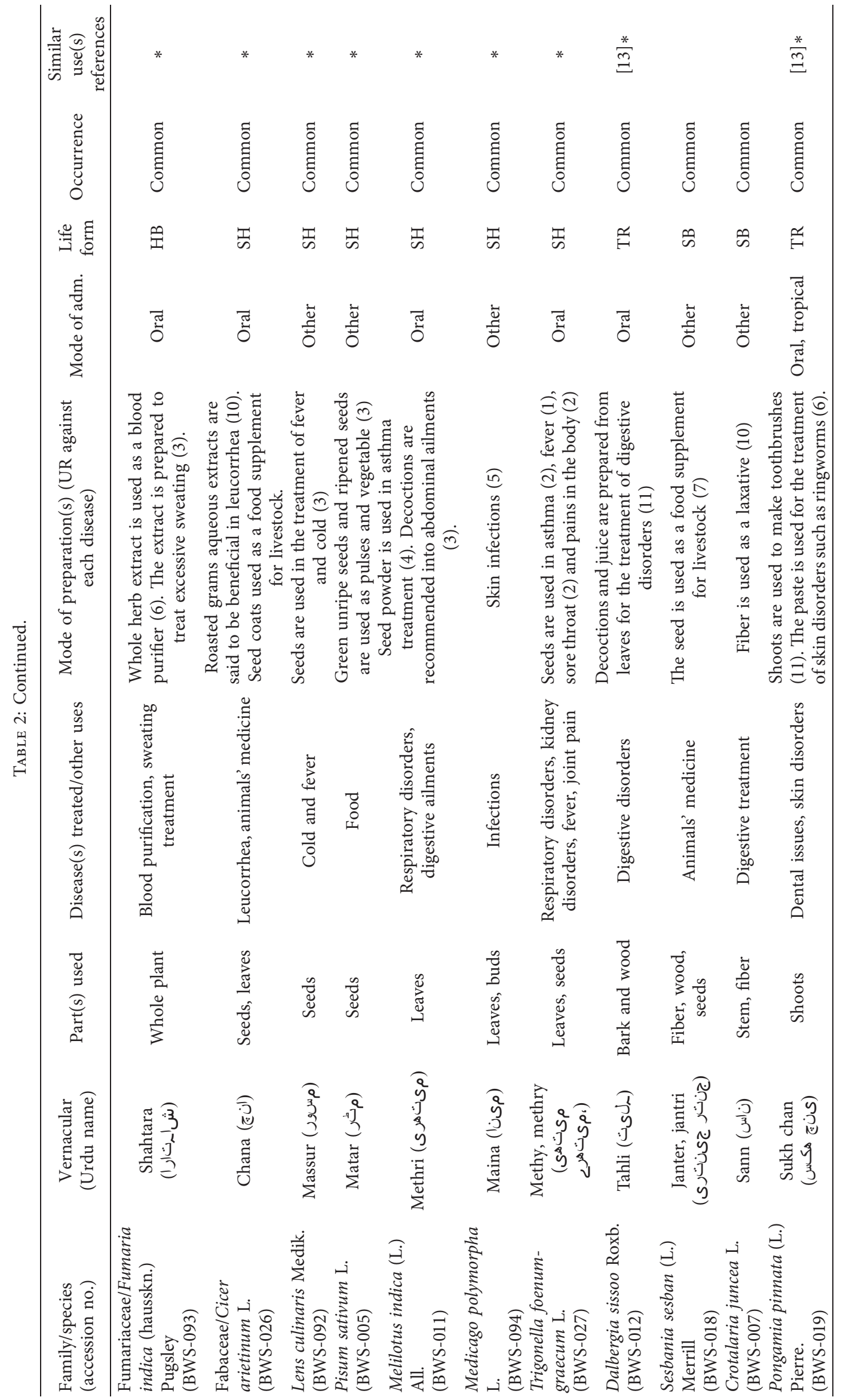




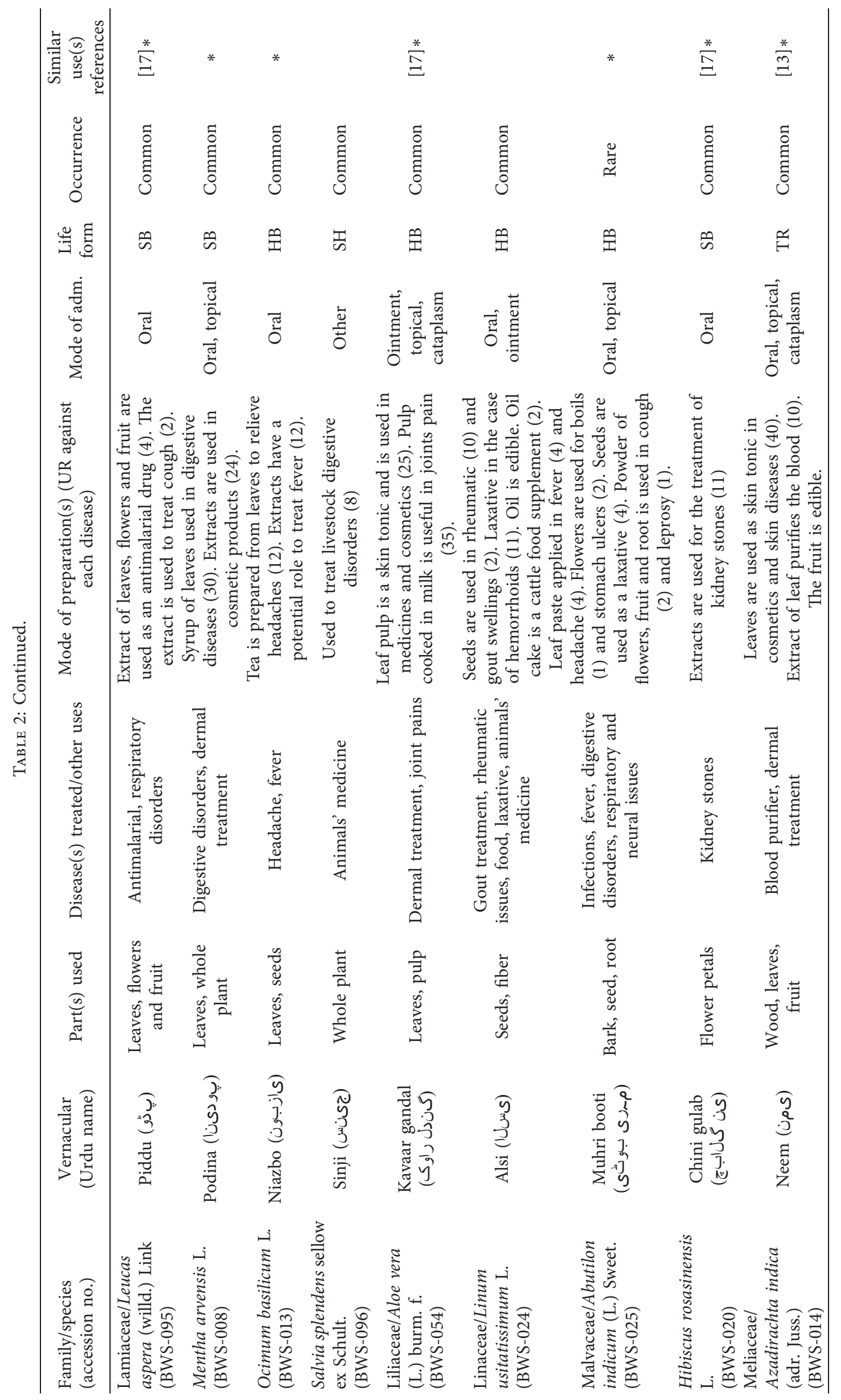




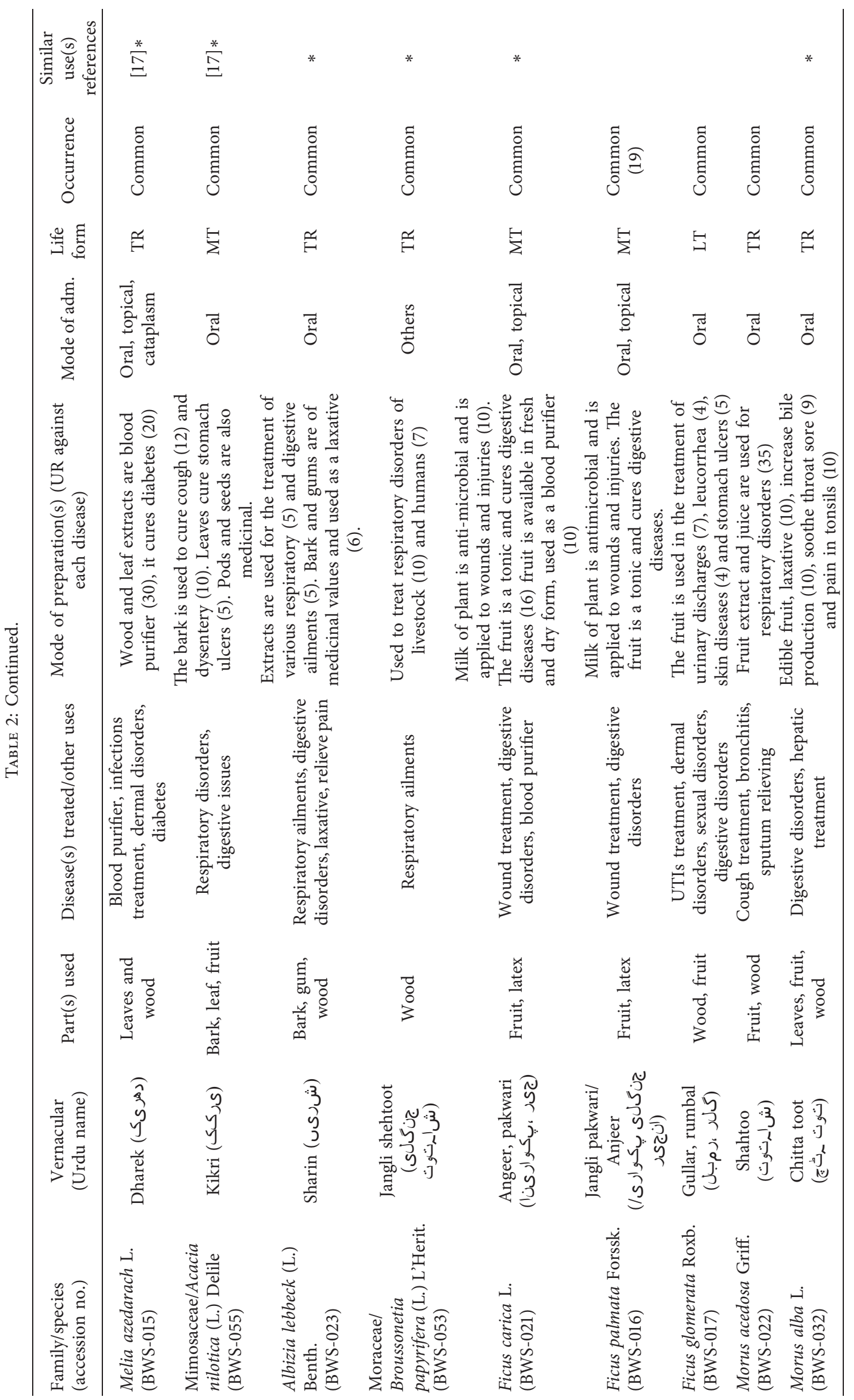




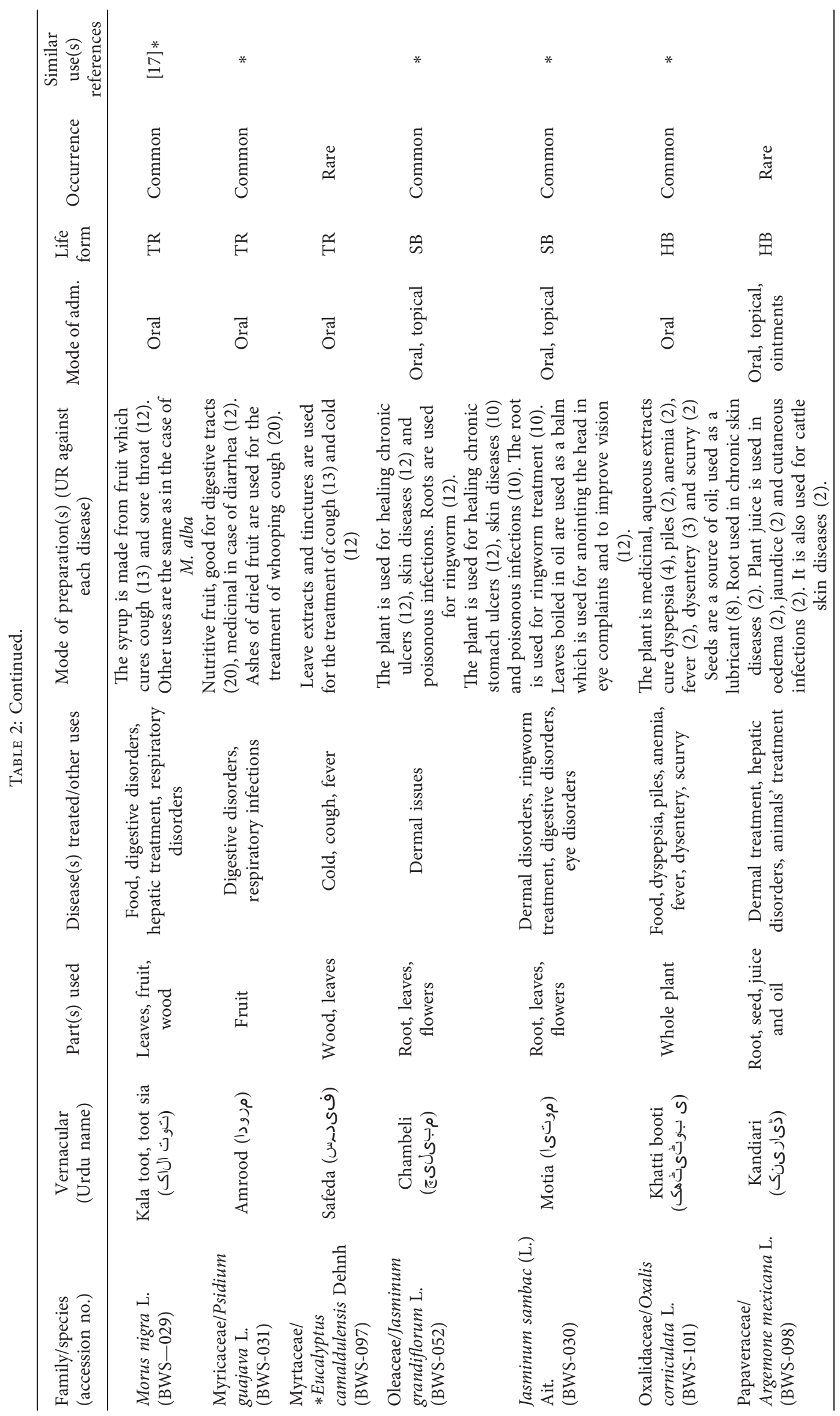




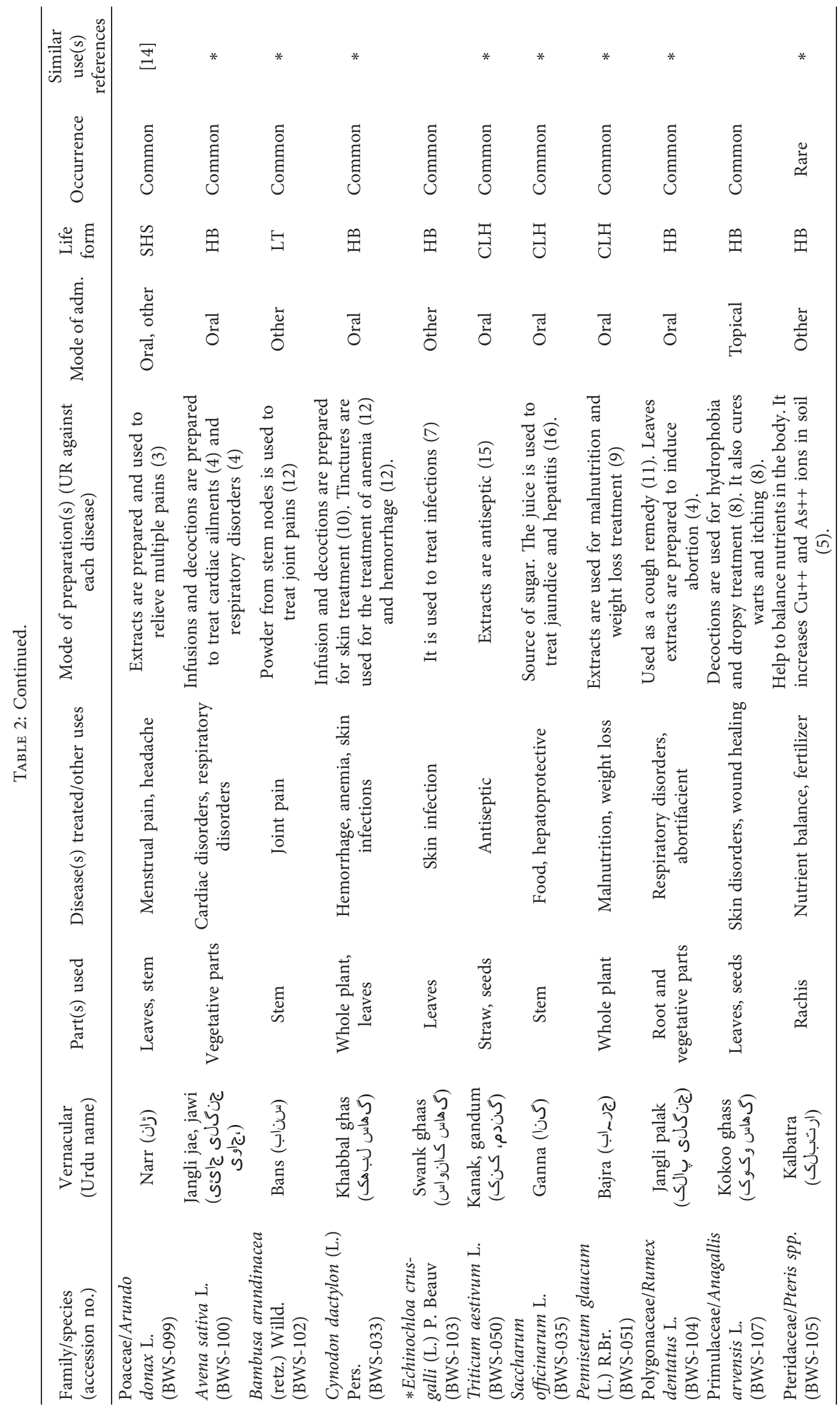




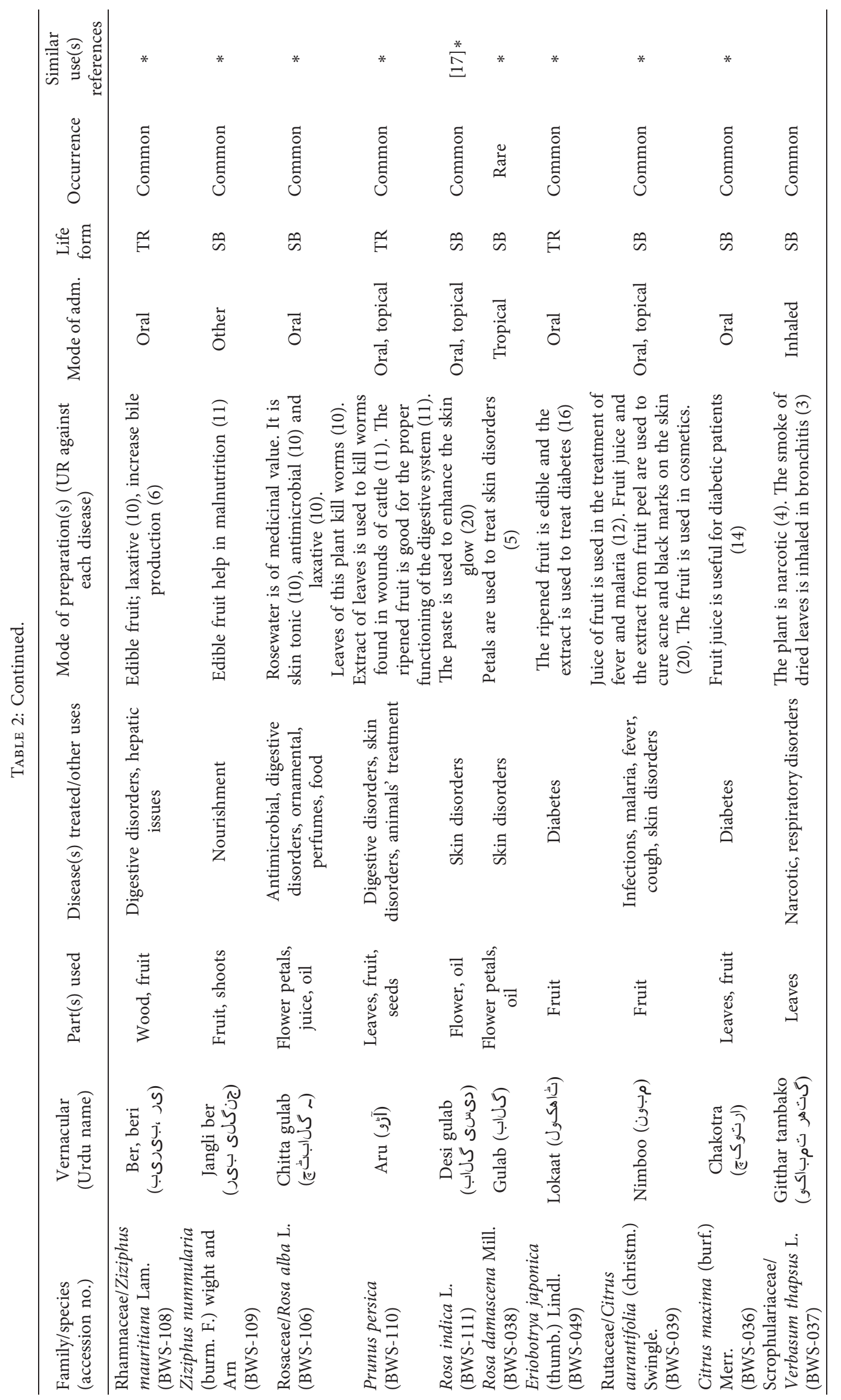




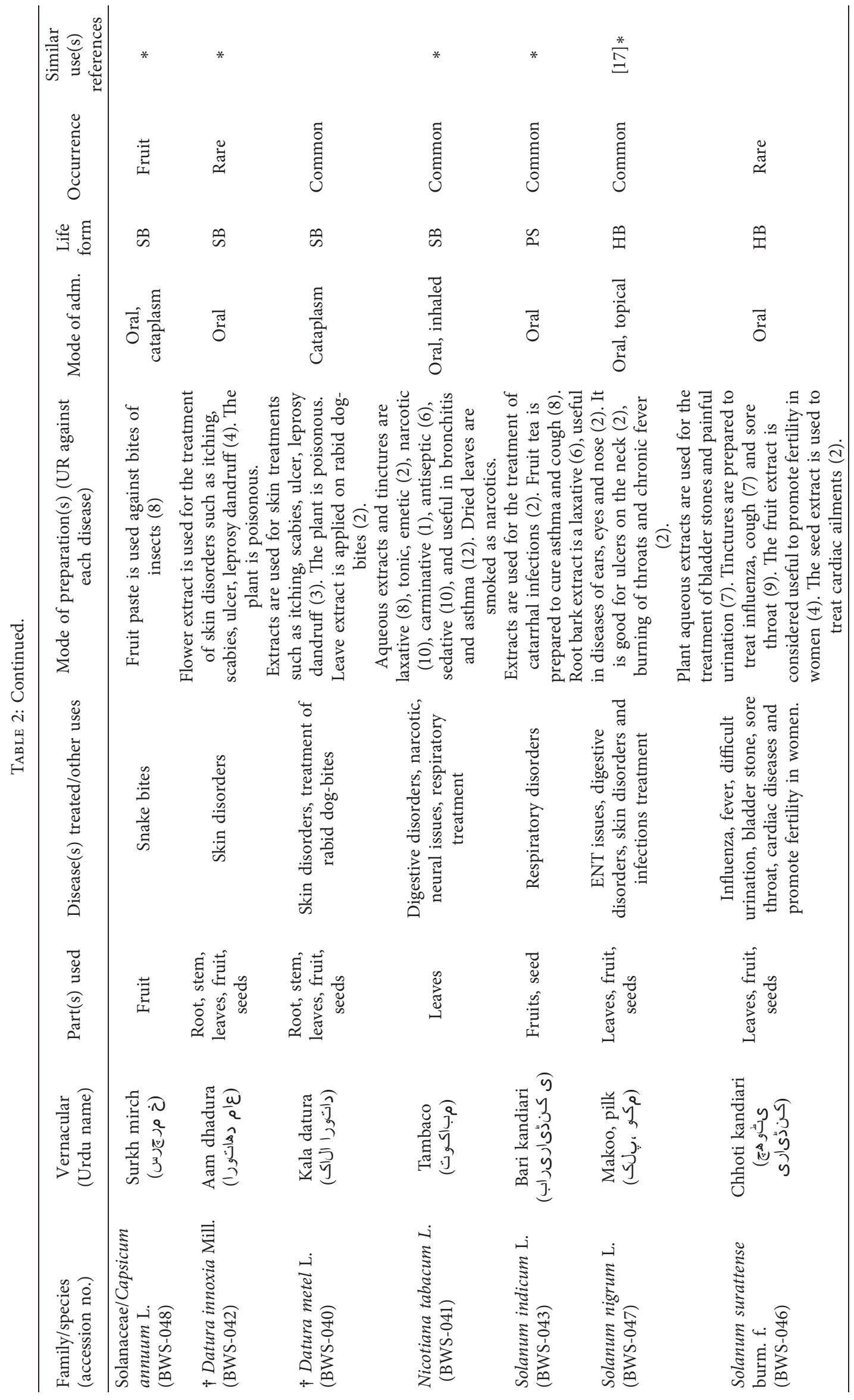




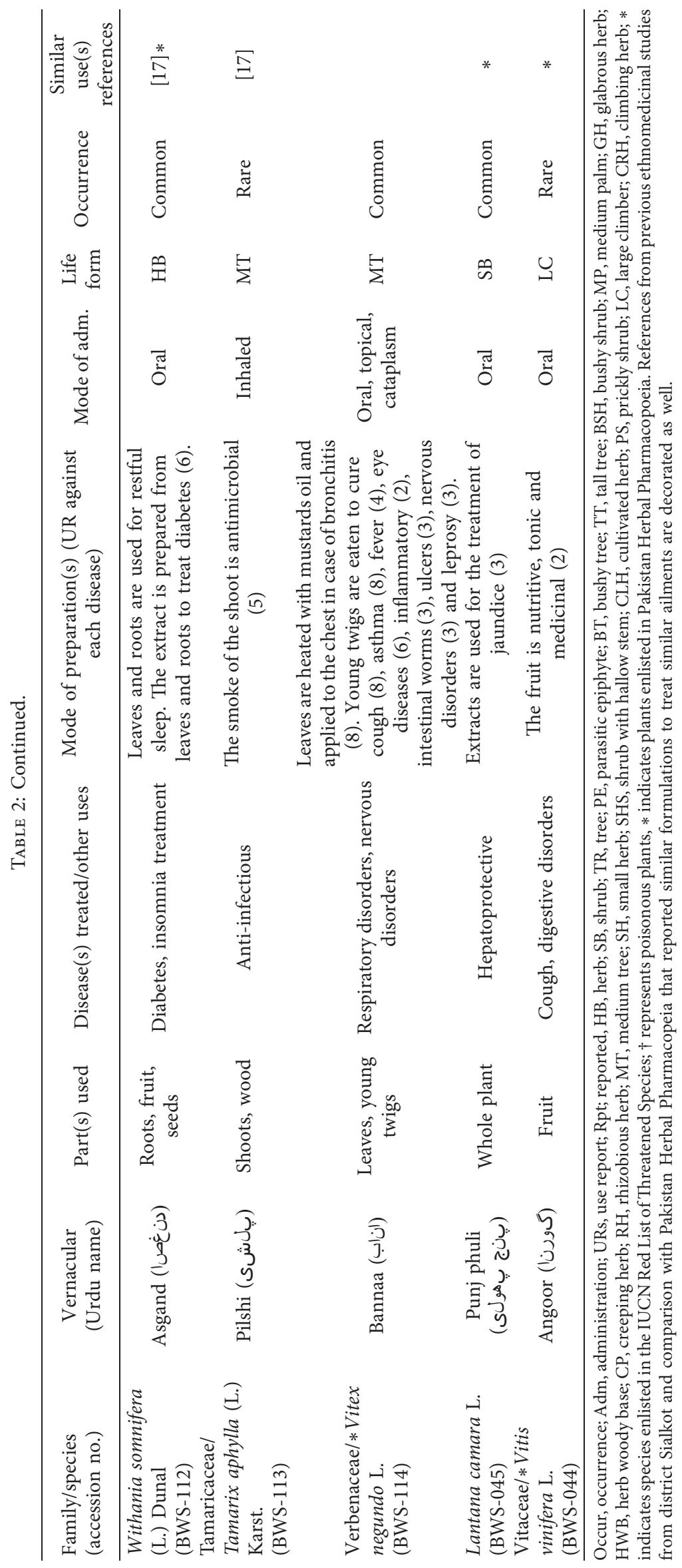




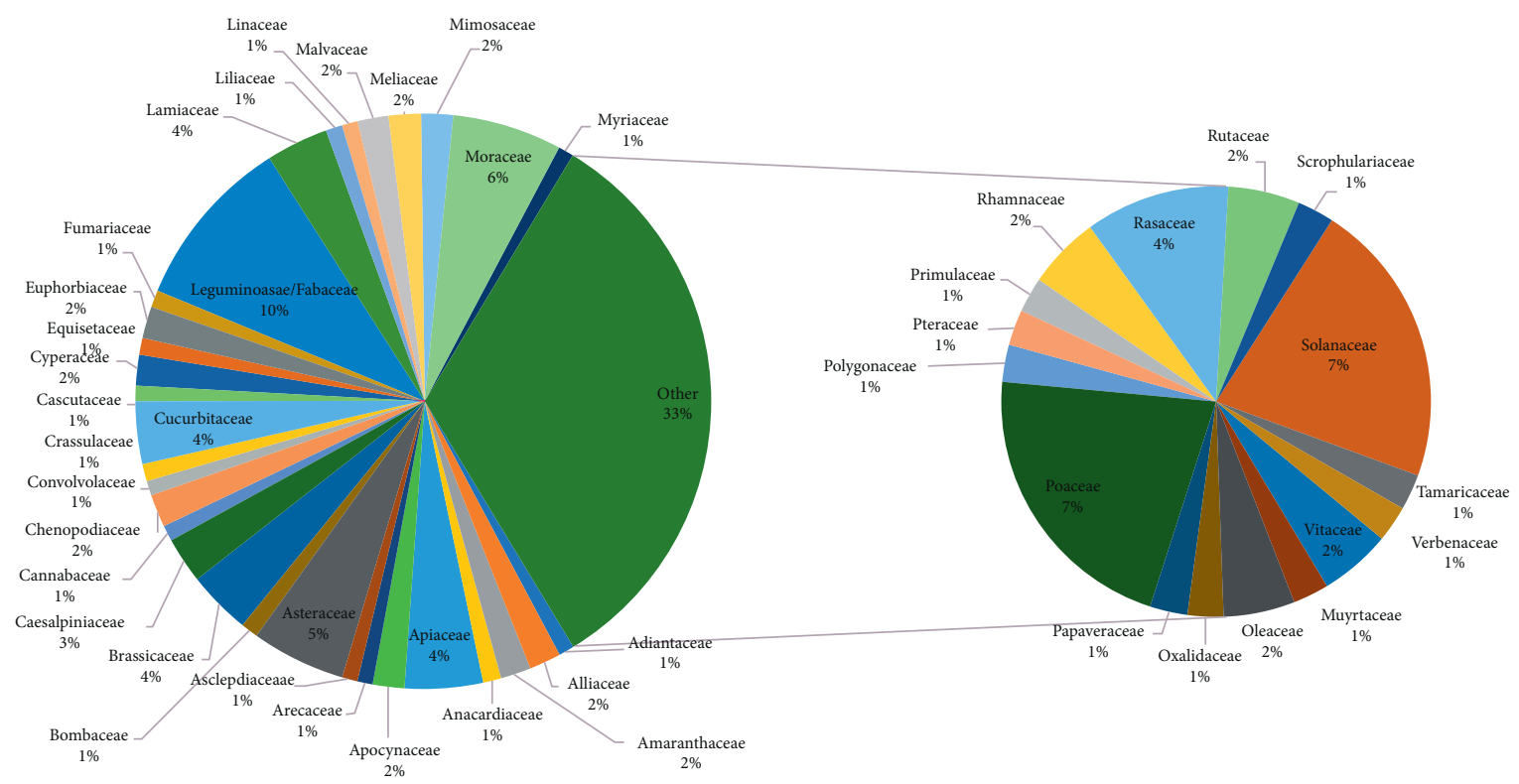

FIgURE 3: The percentage distribution of medicinal plant families among Bajwat Wildlife Sanctuary. 47 families disseminated among 97 genera and 114 medicinal plant species represent the great diversity of plants.

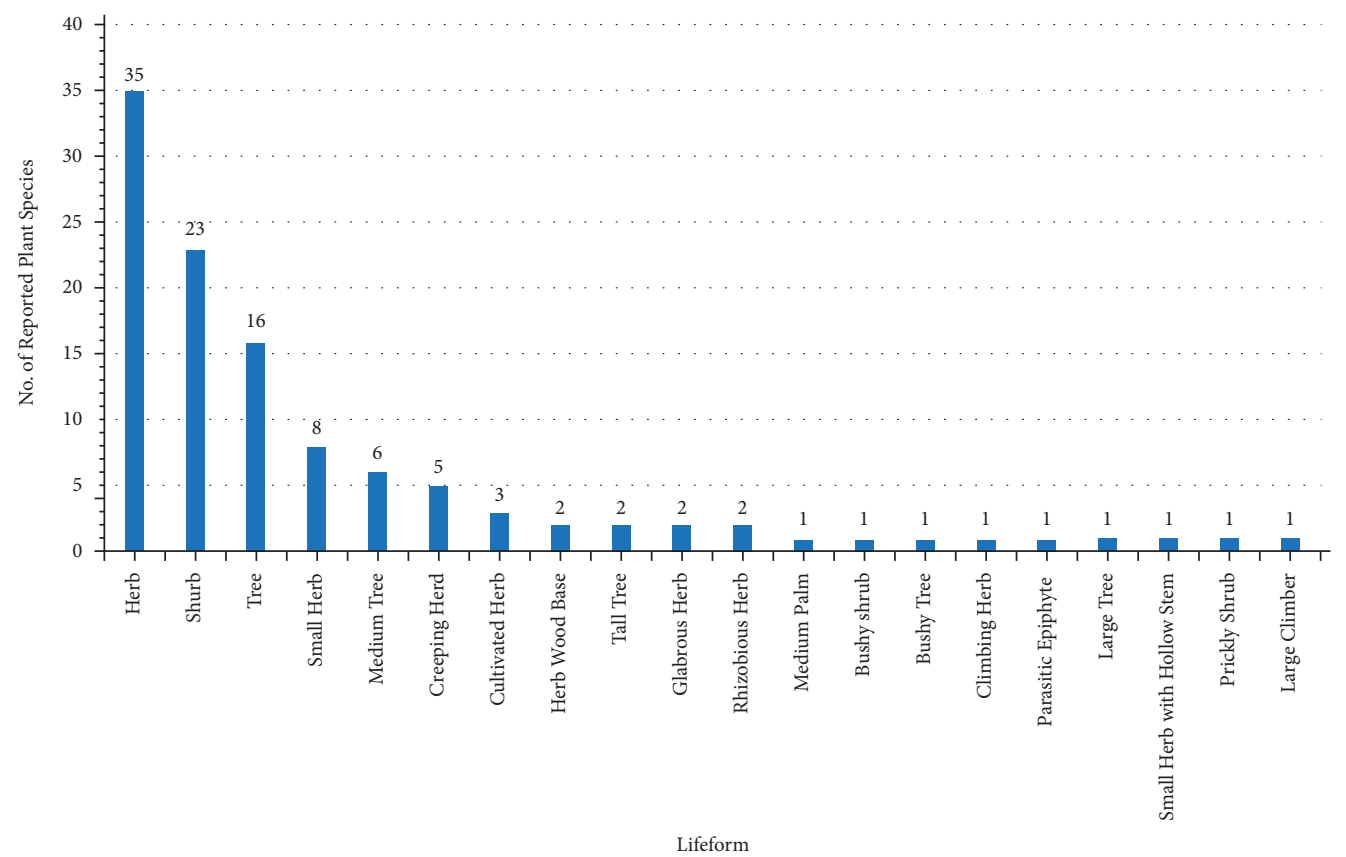

FIGURE 4: The life form of different plant species.

categories which make $38 \%$ in total. The great proportion of leaves and fruits in herbal formulations show their significance because of the presence of various phytochemicals that are present in these plant parts, while another reason is the ease of availability of these parts. Wood or bark (12\%), latex $(10 \%)$, and flowers (10\%) were reported likewise followed by roots $(7 \%)$ and herbaceous stems (7\%). 11\% of the formulations reported the use of the whole plant body, while 5\% reported the use of plants as a source of dietary fibers. Some formulations also reported the use of rhizomes or bulbs for the preparation of medicines. Some studies on the ethnomedicinal flora of Sialkot also reported the use of different plant parts in various herbal medicines dominated using leaves, fruits, and herbaceous stems, which is in favor of our study $[13,14,16,17]$.

3.4. Preparation of Ethnopharmacological Formulations. Preparation of crude plant formulations involves the use of potential phytometabolites to treat ailments. The potency of a herbal drug to cure disease depends greatly on the method of preparation that in actual is the manipulation of the 


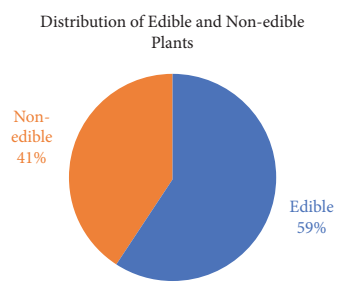

(a)

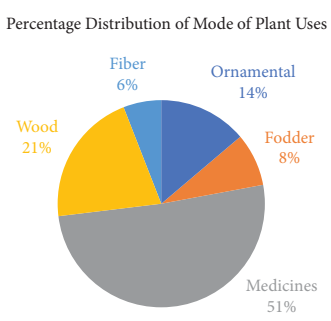

(b)

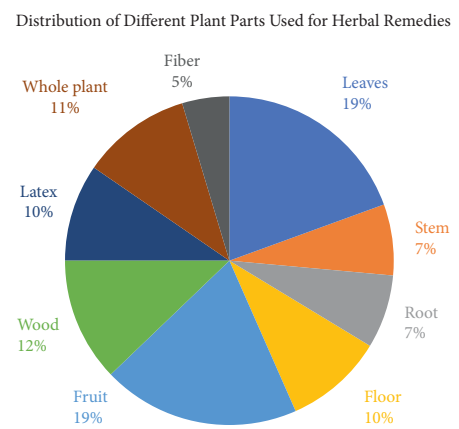

(c)

FIgURE 5: (a) The percentage distribution of the edible and nonedible plants. (b) The percentage distribution of the modes of the plant used. (c) The distribution of different parts of plants for making herbal formulation.

phyto-secondary metabolites to transfer their full potential from the plant part to the perilous part of the body. Table 2 reports the use of medicinal plants in crude herbal formulations against various pathophysiological conditions. This ethnopharmacological survey reported (Figure 6) the use of plant extracts (32\%) as a major method for the preparation of herbal drugs, while $11 \%$ of the herbal formulations were prepared in the form of decoctions. Some of the herbal remedies were used in the form of food (10\%), oil $(10 \%)$, and fresh plant materials $(6 \%)$, while other herbal formulations involved cooking (5\%) in the the form of food. The preparation of the ethnopharmacological formulations by the inhabitants of the studied area shows that the food medicinal portion is essential to treat the ailments. The people of Bajwat reported that the consumption of crude herbal drugs as food plays a significant role to treat ailments. The inhabitants of Bajwat were adding crude herbal formulations in their routine food and sometimes were preparing special formulations separately to treat ailments. Some of the inhabitants reported the inhalation of smoke (2\%) of wood or other plant material to treat respiratory disorders such as bronchitis, cough, and asthma. A similar number $(2 \%)$ of plant materials were used for the preparation of tincture. $8 \%$ of the total reported plant species were used in animal medicine because of their medicinal importance. Some of the plant species were given to animals as fodder to treat digestive disorders of livestock, to eradicate malnutrition, and used as a food supplement. Few herbal medicines were prepared and applied to animals' skin to cure dermal issues. There is no study reported previously from district Sialkot to determine the mode of preparation of herbal formulations by local inhabitants. Our results are contrary to some previously performed work from different territories of Pakistan that reported powder [25] as the best method for the preparation of herbal formulations because of fewer contamination chances of the powder and easy to preserve and reuse. The people of the Bajwat Wildlife Sanctuary claimed that the preparation of the extract is the most feasible and quick strategy that involves the simple method to prepare formulations and its consumption as fresh can increase the efficacy of a drug in case of any severe ailment.
3.5. Administration of the Ethnopharmacological Drugs. Some of the inhabitants of Bajwat were well aware of the mode of administration and its significance. According to inhabitants, the mode of administration helps to deliver the drug efficiently and timely to the suffering part of the body. Figure 7 encodes various modes of administration of herbal formulations reported by the local inhabitants and healers. The oral route stands up with $69 \%$ of the total formulations reported. The oral route reported the ingestion of the fresh plant material powder, using teas, tinctures, or decoctions prepared from different plant parts. People of Bajwat also used oils as a laxative to cure digestive disorders, or sometimes different oils were taken orally to enhance vitality and to reduce feebleness and promote vigor. The oral intake of oil from some plant species was also reported as an aphrodisiac (e.g., Phoenix dactylifera L.). The second most common mode of administration was reported as the topical application (15\%) of the plant crude drug. The topical administration of the plant material in the form of paste prepared from different plant parts was most common among the inhabitants of Bajwat to treat skin disorders such as acne, skin microbial infections, ringworms, and eczema and to treat burn marks. The topical administration also involved the cosmetic enhancement of the skin glow that includes the use of the paste of Aloe vera, Mentha arvensis aqueous extract spray, and Azadirachta indica paste to cure acne and other skin ailments. The cataplasm makes $7 \%$ of the total reported plant species from the study area that involves the maceration of different plant parts such as root, stem, and leaves and applied on the skin to treat different types of skin wounds and different degrees of burns and disorders. The cataplasm was also reported to play a futile role to act as an antidote against the stings of snakes, insects, and other organisms. The ointments also contribute to $7 \%$ of the reported mode of administration. Most of the ointments were extracted in the form of oils and massaged on the skin surface to cure joint pain and to promote strength among bones and muscles. Very few of the plant materials were smoked (2\%) to cure various respiratory disorders such as asthma, cough, bronchitis, and emphysema. Some of the plant parts such as leaves and flowers were smoked as a narcotic and for recreation such as Nicotiana tabacum, while some were used as tranquilizers 


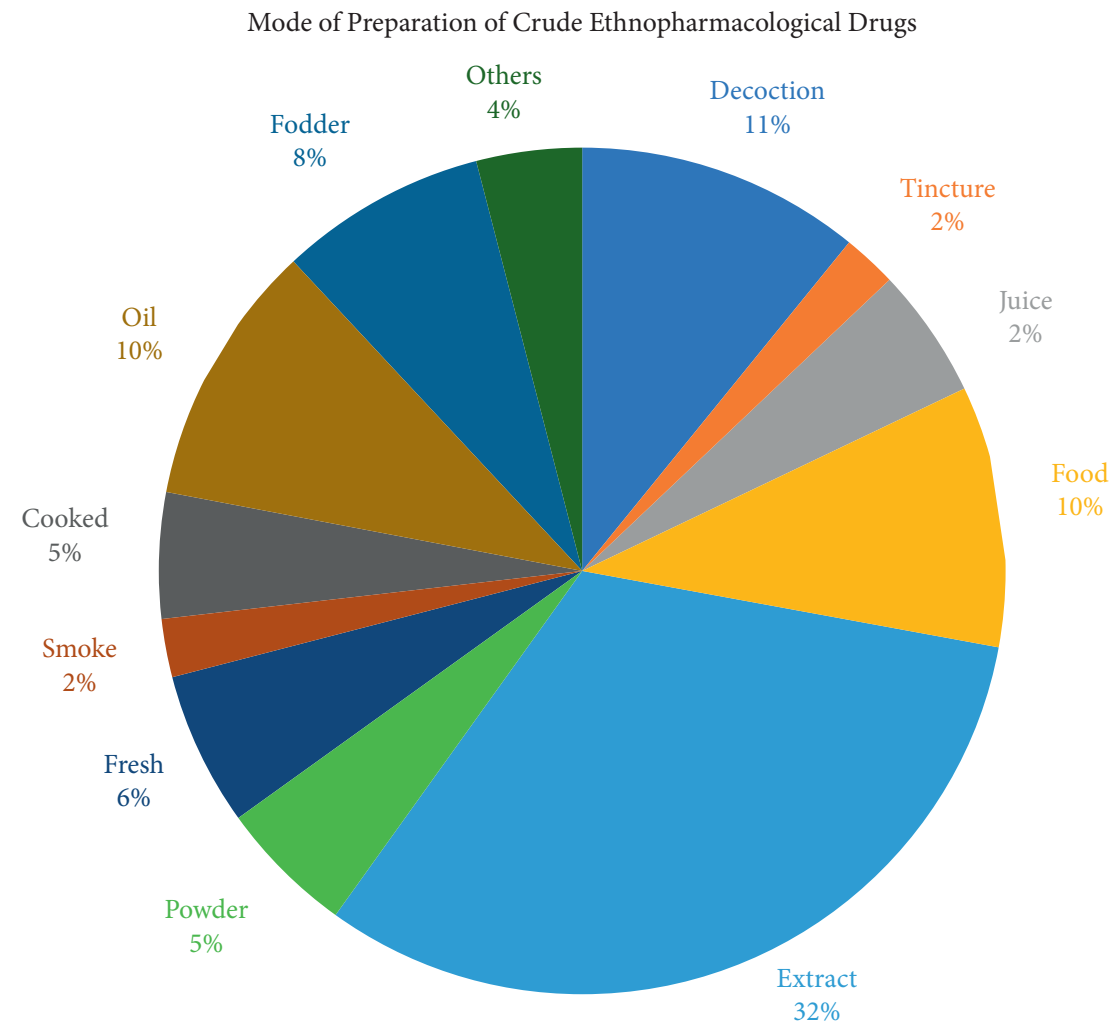

Figure 6: The diagram represents the method of preparation of crude ethnopharmacological drugs.

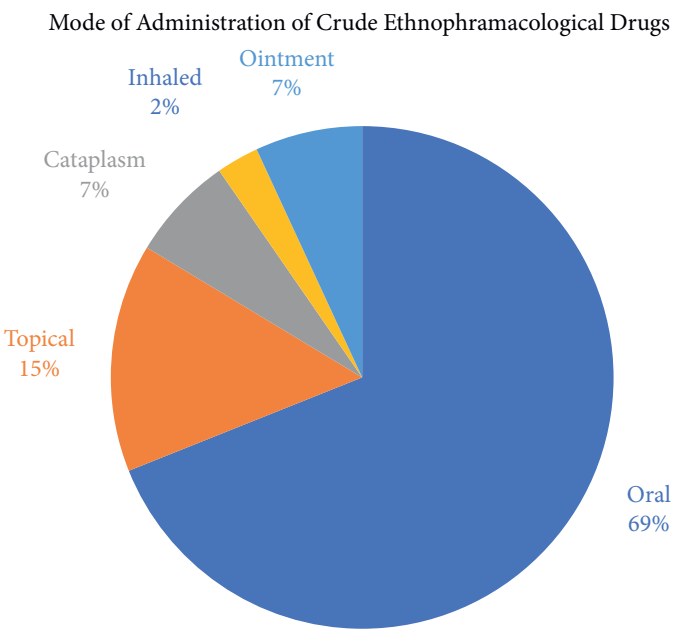

Figure 7: The diagram represents the mode of administration of crude plant drugs.

and sedatives. The oral administration was reported extensively in Pakistan Herbal Pharmacopeia as the major mode of administration of herbal formulations [8]. Some studies performed in the nearby territories of Pakistan $[26,27]$ also reported oral administration as the most common method of administration of herbal drugs.

3.6. Diseases and Pathological Conditions. The digestive disorders were reported most common ailments of the inhabitants of Bajwat which account for $21 \%$ of the total disorders cured (Figure 8). Commonly reported digestive disorders include diarrhea, stomach pain, heart-burning issues, nausea, constipation, abdominal bloating, dyspepsia, and vomiting. Different ailments were categorized according to the WHO International Classification of Primary Care, $2^{\text {nd }}$ Edition, which is used worldwide. Skin disorders were found common among the inhabitants to be treated by crude formulations, and $16 \%$ of the total ailments cured marked to this category. The most common skin ailments among the inhabitants of Bajwat were reported to be eczema, skin boils, acne, skin burns, skin infections, ringworm, and warts. $14 \%$ of respiratory disorders were cured such as cough, asthma, bronchitis, emphysema, and shortness of breath. The rest of the different ailments including fever and malaria (12\%), urinary disorders (10\%), hepatic ailments (9\%), reproductive disorders (7\%), cardiac disorders (6\%), and neurological disorders $(5 \%)$ were cured by using different herbal formulations.

Table 3 shows that a total of 2029 URs were collected from 130 informants against 42 pathophysiological groups by using 114 medicinal plant species, and on average, 48 URs were collected against each disease category. Each medicinal plant species was mentioned $\sim 18$ times to cure the health issues of the local inhabitants ( 18 UR per plant species). 290 URs $(\sim 15 \%)$ were reported from 32 plant species to treat digestive disorders which shows that digestive disorders are the most common ailments prevailing among the inhabitants of the Bajwat Wildlife Sanctuary, while 279 URs $(\sim 14 \%)$ from 27 plant species were mentioned that involved the preparation of different extracts, ointments, and paste for 


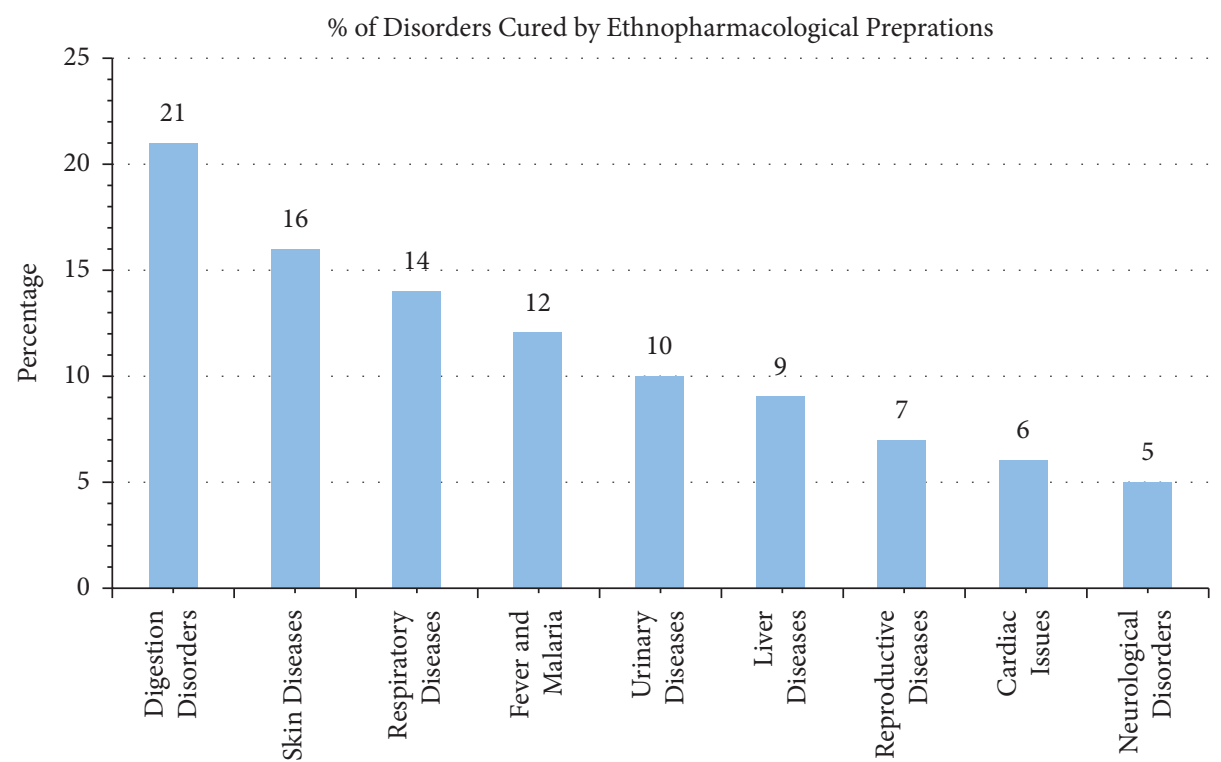

FIGURE 8: The diagram showing the percentage of different disorders cured by using plant formulations.

TABLE 3: Diseases, use report and number of species.

\begin{tabular}{|c|c|c|c|}
\hline ICPC-2 & Disease/action & Use reports & No. Of species \\
\hline W83 & Abortion induced (abortifacient) & 10 & 3 \\
\hline B82 & Anemia & 42 & 4 \\
\hline A26 & Cancer & 3 & 1 \\
\hline K84 & Cardiac disorders & 16 & 3 \\
\hline R09 & Catarrhal inflation (sinus infections) & 10 & 1 \\
\hline D12 & Constipation & 63 & 9 \\
\hline R05 & Cough & 115 & 13 \\
\hline S24 & Dandruff & 10 & 2 \\
\hline W99 & Delivery issues & 16 & 2 \\
\hline D19, D82 & Dental ailments & 20 & 3 \\
\hline T89, Т90 & Diabetes & 70 & 4 \\
\hline D29 & Digestive issues & 290 & 32 \\
\hline D07 & Dyspepsia & 36 & 4 \\
\hline F73 & Eye infections & 15 & 2 \\
\hline $\mathrm{A} 03$ & Fever/febrile/cold & 102 & 18 \\
\hline A10 & Hemorrhage/wounds/stop bleeding & 49 & 8 \\
\hline K86, K87 & Hypertension & 40 & 8 \\
\hline F05 & Impaired vision & 30 & 1 \\
\hline A08 & Inflammation & 17 & 4 \\
\hline A78 & Infections (antimicrobial) & 95 & 11 \\
\hline D13 & Jaundice & 18 & 5 \\
\hline \multirow[t]{2}{*}{ U14 } & Kidney stones & 46 & 8 \\
\hline & Leprosy & 19 & 5 \\
\hline D97 & Liver issues & 65 & 9 \\
\hline A73 & Malaria/dengue & 62 & 5 \\
\hline T91 & Malnutrition & 28 & 3 \\
\hline P85 & Mental retardation & 3 & 1 \\
\hline N99 & Neurological disorders & 50 & 7 \\
\hline \multirow[t]{2}{*}{ A01 } & Pain reliever (analgesic) & 21 & 5 \\
\hline & Piles & 2 & 1 \\
\hline W17, W18 & Postpartum issues/recovery & 5 & 1 \\
\hline R83 & Reproductive disorders & 54 & 6 \\
\hline R96 & Respiratory disorders/asthma & 27 & 6 \\
\hline L99 & Rheumatism & 48 & 3 \\
\hline Y08 & Sexual disorders & 10 & 2 \\
\hline
\end{tabular}


TABle 3: Continued.

\begin{tabular}{lccc}
\hline ICPC-2 & Disease/action & Use reports & No. Of species \\
\hline \multicolumn{1}{c}{ S11, S76 } & Septicemia (blood purifier) & 83 & 8 \\
A77 & Skin infections/disorders & 279 & 27 \\
S12 & Small pox & 2 & 1 \\
D87 & Snake bites and other stings & 39 & 4 \\
U99 & Stomach pain/issues & 77 & 13 \\
D10 & UTIs & 40 & 9 \\
& Vomiting & 2 & 1 \\
\hline
\end{tabular}

ICPC-2; International Classification of Primary Care $-2^{\text {nd }}$ Edition.

oral and topical administrations to treat skin disorders. There was no study performed previously to report the health disorders of the people of the district Sialkot or inhabitants of the Bajwat Wildlife Sanctuary.

3.7. Side Effects of Poisonous Medicinal Plants. The inhabitants of Bajwat reported that most of the plants of the sanctuary do not have any harmful effects. A few species anyway were having dangerous impacts and the nearby individuals keep up broad information about the distinctive poisonous and nonharmful medicinal plants. For instance, the juice of the seeds of Datura innoxia Mill. [28], Datura metel L. [29], and Ricinus communis L. [30] is known to be profoundly harmful. A few plants were reported to have poisonous impacts on both humans and livestock, for example, Calotropis procera (Ait.) and Euphorbia helioscopia L. The latex of the two plants causes harmful impacts through eye and skin contact. Some studies reported that the use of the limited dose of the latex of Euphorbia is beneficial to treat warts and wounds, but excessive and unlimited use of latex can be carcinogenic [21]. Parthenium hysterophorus L. was also reported to be a poisonous plant by local healers and some inhabitants and can cause severe respiratory ailments and was found growing excessively along the roadsides. Although some people in the local market were found using Parthenium hysterophorus L. to decorate flower bouquets, Maleki and Akhani [21] also reported some of the plants mentioned above as poisonous plants from Mountain Taftan, Iran, which is located at the border of Pakistan's southwestern province, Balochistan. The Royal Botanical Garden's annual report [31], stated $8 \%$ of poisonous plants out of the total documented plant uses. However, in the Bajwat Wildlife Sanctuary only 6 plants were reported poisonous which makes $5.26 \%$ of the total reported plant species of the study area.

\subsection{Plants Enlisted in the IUCN Red List of Threatened Plant} Species. The IUCN Red List of Threatened Species provides significant information about the evidence-based extinction and risk assessments of individual plant species. It also contributes to understanding the forces that are responsible for the extinction of species and also helps in management interventions to overcome or delay the extinction. Despite critical evaluation of species at risk of extinction, it is believed that many plant species will be extinct before they have been recognized as being at risk of extinction [32]. Determination of plant species' current status in the IUCN Red List of Threatened Species can greatly help to protect the threatened ethnomedicinal flora of a region. According to the IUCN Red List of Threatened Plant Species, more than 3200 species are threatened with extinction, which makes about $27 \%$ of the total assessed species. Eight out of the total 114 plant species were listed in the IUCN Red List as least concern (LC), including Bauhinia variegate*, Cyperus rotundus L., Cassia fistula L.*, Centella asiatica (L.) Urb.*, Echinochloa crus-galli (L.) P. Beauv, Eclipta prostrata L., Vitis vinifera L.*, and Vitex negundo L. while Eucalyptus camaldulensis Dehnh.* was enlisted as near-threatened (NT). The occurrence of plant species in Bajwat Wildlife Sanctuary was also observed, and 19 species were found rarely distributed, which makes $17 \%$ of the total reported plant species, while 5 species (* placed at the end of their name) out of 19 rarely distributed species were enlisted in the IUCN Red List of Threatened Species (Table 2).

\section{Conclusion}

This study involves the first-ever extensive ethnopharmacological investigation to report the medicinal plants of the Bajwat Wildlife Sanctuary, which is a complex riverine biological ecosystem. We have reported 114 medicinal plant species. The extract preparation (32\%) was reported as the most basic strategy for making herbal formulations, while oral intake (69\%) was observed most common for the administration of drugs among the local community. The highest number of URs against digestive disorders (290 15\%) and skin disorders (279 14\%) show that these are the most common problems among the local inhabitants. The stomach-related issues were seen generally regular among local people and were cured by crude ethnopharmacological formulations. This study embraces the ethnopharmacological knowledge of local healers and inhabitants and reports the exchange of data from generation to generation because of strong communication in families and neighboring communities. The investigation of the ethnomedicinal information and their comparison with past reports from the district Sialkot, and Pakistan Herbal Pharmacopeia endorses the enlisted knowledge of local healers and inhabitants to prepare formulations against multiple disease categories. About $75 \%$ of the enlisted medicinal plant species were not reported previously in 
research reports from Sialkot, while $21 \%$ of novel herbal formulations were documented in comparison with the Pakistan Herbal Pharmacopeia. This study likewise explains the importance of the studied zone and the incredibly assorted diversity of plants and its status to help plant species to develop unreservedly without human mediation.

\section{Data Availability}

The data used to support the findings of this study are included within the article.

\section{Ethical Approval}

This study does not involve any human or animal experiments. The study was approved by the University Bioethical Committee, and the data were recorded from local inhabitants/participants after oral consent.

\section{Conflicts of Interest}

The authors declare no conflicts of interest.

\section{Authors' Contributions}

BJ, WI, MS, HABA, and WH devised the study, collected and identified plant specimens, and interviewed inhabitants. BJ wrote and revised the manuscript and analyzed data. BJ, WI, MS, HABA, AS, and ZRM were added to the subsequent drafts. The authors read and finalized the manuscript for submission. Sidra Ahsan Shah, Wajeeha Iqbal, Muneeba Sheraz, and Bilal Javed are equally contributed first authors.

\section{References}

[1] K. Agarwal and R. Varma, "Ethnobotanical study of antilithic plants of Bhopal district," Journal of Ethnopharmacology, vol. 174, pp. 17-24, 2015.

[2] S. H. Shaikh, F. Malik, H. James, and H. Abdul, "Trends in the use of complementary and alternative medicine in Pakistan: a population-based survey," Journal of Alternative \& Complementary Medicine, vol. 15, no. 5, pp. 545-550, 2009.

[3] A. M. Abbasi, M. A. Khan, M. H. Shah, M. M Shah, A Pervez, and M Ahmad, "Ethnobotanical appraisal and cultural values of medicinally important wild edible vegetables of Lesser Himalayas-Pakistan," Journal of Ethnobiology and Ethnomedicine, vol. 9, no. 1, pp. 66-13, 2013.

[4] S. Bibi, J. Sultana, H. Sultana, and R. N. Malik, "Ethnobotanical uses of medicinal plants in the highlands of soan valley, salt range, Pakistan," Journal of Ethnopharmacology, vol. 155, no. 1, pp. 352-361, 2014.

[5] S. Arshad, H. Waris, M. Ismail, and A. Naseer, "Health care system in Pakistan: a review," Research in Pharmacy and Health Sciences, vol. 2, no. 3, pp. 211-216, 2016.

[6] A. Ghaffar, B. Kazi, and M. Salman, "Health care systems in transition III. Pakistan, Part I. An overview of the health care system in Pakistan," Journal of Public Health, vol. 22, no. 1, pp. $38-42,2000$.

[7] B. T. Shaikh and J. Hatcher, "Complementary and alternative medicine in Pakistan: prospects and limitations," Evidencebased Complementary and Alternative Medicine, vol. 2, no. 2, pp. 139-142, 2005.
[8] H. R. H. Malik, Tibbi Pharmacopoeia Pakistan, National Council For Tibb Islamabad Pakistan, Islamabad, Pakistan.

[9] A. S. H. A. Alamgeer, A Sharif, H Asif et al., "Indigenous medicinal plants of Pakistan used to treat skin diseases: a review," Chinese Medicine, vol. 13, no. 1, pp. 52-26, 2018.

[10] C. Union, IUCN Directory of South Asian Protected Areas, 2011.

[11] M. A. Bhinder, M. Iqbal, M. Shahbaz, M. Y. Zahoor, and W. Shehzad, "Avian biodiversity of Bajwat wetland, district Sialkot. Pakistan,” J. Anim. Plant Sci.vol. 25, no. 3, pp. 416422, 2015.

[12] S. Salma, S. Rehman, and M. Shah, "Rainfall trends in different climate zones of Pakistan," Pakistan J. Meteorol.vol. 9, no. 17, pp. 37-47, 2012.

[13] A. Mahmood, A. Mahmood, and A. Tabassum, "Ethnomedicinal survey of plants from district Sialkot, Pakistan," Journal of Applied Pharmacology, vol. 02, no. 2, pp. 212-220, 2012.

[14] S. Ikram, K. H. Bhatti, and M. Parvaiz, "Ethnobotanical studies of aquatic plants of district Sialkot, Punjab (Pakistan)," Journal of Medicinal Plants Studies, vol. 2, no. 21, pp. 58-63, 2014.

[15] S. Ikram and M. Ahmed, Aquatic Plants of Sialkot District, 2013.

[16] A. Zereen, Z.-u.-d. Khan, and A. A. Sardar, "Ethnobotanical studies of wild herbs of central Punjab, Pakistan," Bangladesh Journal of Plant Taxonomy, vol. 20, no. 1, pp. 67-76, 2013.

[17] M. Farrukh Nisar, M. Arshad, and F. Nisar, "“Ethnomedicinal flora in district Sialkot, Punjab, Pakistan," middle-east," journal of scientific research, vol. 9, no. 2, pp. 209-214, 2011.

[18] M. C. Peel, B. L. Finlayson, and T. A. McMahon, "Updated world map of the Köppen-Geiger climate classification," Hydrology and Earth System Sciences, vol. 11, no. 5, pp. 439-473, 2007.

[19] B. Javed, W. Seerat, A. Sarwer, and Z.-R. Mashwani, "Ethnopharmacological approaches of the native hill people of murree and kotli sattian, district rawalpindi, province of Punjab, Pakistan," Botany Letters, vol. 167, pp. 1-17, 2020.

[20] M. Al-Fatimi, "Ethnobotanical survey of medicinal plants in central Abyan governorate, Yemen," Journal of Ethnopharmacology, vol. 241, p. 111973, 2019.

[21] T. Maleki and H. Akhani, "Ethnobotanical and ethnomedicinal studies in Baluchi tribes: a case study in Mt. Taftan, southeastern Iran," Journal of Ethnopharmacology, vol. 217, pp. 163-177, 2018.

[22] C. Yebouk, F. Z. Redouan, G. Benítez et al., "Ethnobotanical study of medicinal plants in the Adrar Province, Mauritania," Journal of Ethnopharmacology, vol. 246, p. 112217, 2020.

[23] C. Lee, S.-Y. Kim, S. Eum et al., "Ethnobotanical study on medicinal plants used by local Van Kieu ethnic people of Bac Huong Hoa nature reserve, Vietnam," Journal of Ethnopharmacology, vol. 231, pp. 283-294, 2019.

[24] M. Rashid, N. Ali, and S. Afzal, "Ethnomedicinal plant use value in the Lakki Marwat district of pakistan," Journal of Ethnopharmacology, vol. 158, pp. 1-11, 2014.

[25] S. Kayani, M. Ahmad, M. Zafar et al., "Ethnobotanical uses of medicinal plants for respiratory disorders among the inhabitants of Gallies - abbottabad, Northern Pakistan," Journal of Ethnopharmacology, vol. 156, pp. 47-60, 2014.

[26] N. Ahmed, A. Mahmood, A. Mahmood, and Z. Sadeghi, "Ethnopharmacological importance of medicinal flora from the district of Vehari, Punjab province, Pakistan," Journal of Ethnopharmacology, vol. 168, 2015. 
[27] N. Ahmed, A. Mahmood, and A. Ashraf, "Ethnopharmacological relevance of indigenous medicinal plants from district Bahawalnagar, Punjab, Pakistan," Journal of Ethnopharmacology, vol. 175, 2015.

[28] A. Alamgeer, A. M. Uttra, H. Ahsan, U. H. Hasan, and M. A. Chaudhary, "Traditional medicines of plant origin used for the treatment of inflammatory disorders in Pakistan: a review," Journal of Traditional Chinese Medicine, vol. 38, no. 4, pp. 636-656, 2018.

[29] A. Tariq, M. Adnan, A. Iqbal et al., "Ethnopharmacology and toxicology of Pakistani medicinal plants used to treat gynecological complaints and sexually transmitted infections," South African Journal of Botany, vol. 114, pp. 132-149, 2018.

[30] M. F. Qaseem, R. Qureshi, M. S. Amjad, W. Ahmed, A. Masood, and H. Shaheen, "Ethno-botanical evaluation of indigenous flora from the communities of rajh mehal and goi union councils of district kotli, azad Jammu Kashmir Pakistan," Applied Ecology and Environmental Research, vol. 17, no. 2, pp. 2799-2829, 2019.

[31] RBG, "State of the world's plants 2016," Royal Botanic Gardens, Kew, vol. 14, no. 1, pp. 1-8, 2016.

[32] RBG, "State of the world's plants 2017," Royal Botanic Gardens, Kew, vol. 100, 2017. 